\title{
Investigation of the aerosol-cloud-rainfall association over the Indian summer monsoon region
}

\author{
Chandan Sarangi ${ }^{1}$, Sachchida Nand Tripathi ${ }^{1}$, Vijay P. Kanawade ${ }^{1, a}$, Ilan Koren ${ }^{2}$, and D. Sivanand Pai ${ }^{3}$ \\ ${ }^{1}$ Department of Civil Engineering and Centre for Environmental Science and Engineering, \\ India Institute of Technology, Kanpur, India \\ ${ }^{2}$ Department of Earth and Planetary Science, Weizmann Institute, Rehovot, Israel \\ ${ }^{3}$ India Meteorological Department, Pune, India \\ ${ }^{a}$ currently at: University Centre for Earth and Space Sciences, University of Hyderabad, Hyderabad, India \\ Correspondence to: Sachchida Nand Tripathi (snt@iitk.ac.in)
}

Received: 24 October 2016 - Discussion started: 25 November 2016

Revised: 14 March 2017 - Accepted: 23 March 2017 - Published: 21 April 2017

\begin{abstract}
Monsoonal rainfall is the primary source of surface water in India. Using 12 years of in situ and satellite observations, we examined the association of aerosol loading with cloud fraction, cloud top pressure, cloud top temperature, and daily surface rainfall over the Indian summer monsoon region (ISMR). Our results showed positive correlations between aerosol loading and cloud properties as well as rainfall. A decrease in outgoing longwave radiation and an increase in reflected shortwave radiation at the top of the atmosphere with an increase in aerosol loading further indicates a possible seminal role of aerosols in the deepening of cloud systems. Significant perturbation in liquid- and icephase microphysics was also evident over the ISMR. For the polluted cases, delay in the onset of collision-coalescence processes and an enhancement in the condensation efficiency allows for more condensate mass to be lifted up to the mixed colder phases. This results in the higher mass concentration of larger-sized ice-phase hydrometeors and, therefore, implies that the delayed rain processes eventually lead to more surface rainfall. A numerical simulation of a typical rainfall event case over the ISMR using a spectral bin microphysical scheme coupled with the Weather Research Forecasting (WRF-SBM) model was also performed. Simulated microphysics also illustrated that the initial suppression of warm rain coupled with an increase in updraft velocity under high aerosol loading leads to enhanced super-cooled liquid droplets above freezing level and ice-phase hydrometeors, resulting in increased accumulated surface rainfall. Thus, both observational and numerical analysis suggest that high
\end{abstract}

aerosol loading may induce cloud invigoration, thereby increasing surface rainfall over the ISMR. While the meteorological variability influences the strength of the observed positive association, our results suggest that the persistent aerosol-associated deepening of cloud systems and an intensification of surface rain amounts was applicable to all the meteorological sub-regimes over the ISMR. Hence, we believe that these results provide a step forward in our ability to address aerosol-cloud-rainfall associations based on satellite observations over the ISMR.

\section{Introduction}

Aerosol-cloud-rainfall interactions and their feedbacks pose one of the largest uncertainties in understanding and estimating anthropogenic contribution of aerosols to climate forcing (Forster et al., 2007; Lohmann and Feichter, 2005). A fraction of aerosol particles becomes activated as cloud condensation nuclei $(\mathrm{CCN})$ to form the fundamental requisite for cloud droplet formation. Thus, perturbations in regional aerosol loading not only influence the radiation balance directly but also indirectly via perturbing the cloud properties and thereby the hydrological cycle (Ramanathan et al., 2001).

An increase in aerosol loading near the cloud base decreases the cloud droplet size and increases the cloud droplet number concentration (Fitzgerald and Spyers-Duran, 1973; Squires, 1958; Squires and Twomey, 2013; Twomey, 
1974, 1977; Warner and Twomey, 1967) These microphysical changes initiate many feedbacks. The narrowing of the droplet size distribution was suggested to delay the onset of droplet collision-coalescence processes, thereby enhancing the cloud lifetime (Albrecht, 1989), and the delay of raindrop formation (Khain, 2009; Rosenfeld, 1999, 2000). However, recent studies show that an aerosol-induced initialstage suppression of raindrop formation provides the feedback mechanism for a change in microphysical-dynamical coupling within convective clouds, and results in the formation of deeper and wider invigorated clouds (Andreae et al., 2004; Koren et al., 2005). For convective clouds with a warm base, the activation and water supply all start in the warm part near the cloud base. The enhancement in droplet condensation releases more latent heat and, therefore, enhances updraft (Dagan et al., 2015; Pinsky et al., 2013; Seiki and Nakajima, 2014). At the same time, smaller droplets will have smaller effective terminal velocity (i.e., better mobility) and, therefore, will be lifted higher into the atmosphere by the enhanced updrafts (Heiblum et al., 2016; Ilan et al., 2015). Stronger updrafts and smaller effective terminal velocity result in more liquid mass being pushed up to the mixed and cold phases. Smaller-sized droplets will freeze higher in the atmosphere (Rosenfeld and Woodley, 2000), releasing the freezing latent heat into a relatively colder environment, boosting the updrafts and further invigorating the cloud system (Altaratz et al., 2014; Andreae et al., 2004; Khain et al., 2008; Koren et al., 2005). Hence, aerosol abundance can eventually cause an intensification of the precipitation rate due to the cloud-invigorating effect under convective conditions (Koren et al., 2014, 2012; Li et al., 2011).In contrast, under low cloud fraction conditions, the presence of a high concentration of absorbing aerosols induces the aerosol semi-direct effect causing cloud inhibition (Ackerman et al., 2000; Koren et al., 2004; Rosenfeld, 1999) and thereby a reduction in surface rainfall. Thus, the aerosolcloud associations observed over any given region are the net outcome of these competing aerosol effects on clouds (Koren et al., 2008; Rosenfeld et al., 2008). Our present understanding of the sign as well as the magnitude of change in accumulated surface rainfall due to aerosols is inadequate. Besides, aerosol-cloud-rainfall associations are highly sensitive to variation in thermodynamical and environmental conditions, cloud properties, and aerosol types (Khain et al., 2008; Lee, 2011; Tao et al., 2012), further complicating these interactions. Moreover, clouds and precipitation can also interact with aerosols through wet-scavenging process (Grandey et al., 2013, 2014; Yang et al., 2016). Global model simulations illustrated that wet scavenging can cause a strong negative cloud-fraction-AOD (aerosol optical depth) correlation over the tropics (Grandey et al., 2013). The wet-scavenging effect can also generate a similar negative rain-rate-AOD association in the tropical and midlatitude oceans (Grandey et al., 2014).
The Indian summer monsoon is the lifeline for regional ecosystems and water resources, and plays a crucial role in India's agriculture and economy (Webster et al., 1998). The Indian summer monsoon from June through September (JJAS) provides about $75 \%$ of the annual rainfall over central and northern India. Variation in daily rainfall during summer monsoon rainfall is directly linked to India's kharif food grain production (Preethi and Revadekar, 2013). A rapid increase in population and industrialization over the last 2 decades has also resulted in high anthropogenic aerosol loading over northern India, particularly in the Gangetic Basin (Dey and Di Girolamo, 2011). Consequently, the net impact of such large continental aerosol loading on cloud properties and daily surface rainfall in India is an important question that requires utmost attention. Recent studies based on the aerosol direct effect have shown different plausible pathways of aerosol impact on rainfall. Lau and Kim (2006) have shown that an aerosol-induced atmospheric heating over Himalayan slopes and the Tibetan Plateau during the monsoon onset period intensifies the northward shift of the Indian summer monsoon, causing a reduction in rainfall over the Indian summer monsoon region (ISMR). On the other hand, a high aerosol loading also induces a solar dimming (absorbing) effect at the surface (Ramanathan and Carmichael, 2008; Ramanathan et al., 2001), which can alter the land-ocean thermal gradient and weaken the meridional circulation, resulting in a drying trend in seasonal rainfall during the Indian summer monsoon (Bollasina et al., 2011; Ganguly et al., 2012). The present of higher concentrations of absorbing aerosols over northern India is shown to induce a stronger northsouth temperature difference, which fosters an enhancement in moisture convergence from the ocean and a transition of a break spell of the Indian summer monsoon (ISM) into an active spell of ISM (Manoj et al., 2011). Further, this aerosol radiative effect causes an increase in the moist static energy, the invigoration of convection, and eventually more rainfall over India during the following active phase (Hazra et al., 2013; Manoj et al., 2011). These studies provide valuable insight into different pathways of aerosols' radiative impact on the monsoon dynamics and seasonal rainfall over India. However, the microphysical aspect of aerosols' impact on the sign and the magnitude of the monsoonal rainfall over the ISMR is largely unknown (Rosenfeld et al., 2014). Nevertheless, a few recent studies have indicated the existence of a strong aerosol microphysical effect on cloud systems over the ISMR (Konwar et al., 2012; Manoj et al., 2012; Prabha et al., 2012; Sarangi et al., 2015; Sengupta et al., 2013). Conversely, the summer monsoon plays an important role in determining variation in aerosol loading over India by bringing clean marine air and wet scavenging, which are as important as emissions in determining aerosol concentration ( $\mathrm{Li}$ et al., 2016). It has also been shown that aerosols over the Indian Ocean interact with seasonal changes over the ISMR (Corrigan et al., 2006). 
Table 1. Summary of daily dataset used in our analysis. LT refers to local time; TOA: top of the atmosphere; SW: shortwave; LW: longwave.

\begin{tabular}{|c|c|c|c|}
\hline Data source & Parameters & Temporal resolution (LT) & Time period \\
\hline $\mathrm{IMD}^{*}$ & Accumulated rainfall & $08: 30-08: 30$ & $2002-2013$ \\
\hline MODIS Aqua L3 (c5.1) & AOD, CF, CTT, and CTP & $13: 30$ & 2002-2013 \\
\hline CloudSat* 2B (V8) & $\begin{array}{l}\text { Mass concentration and effective radius of liquid- } \\
\text { and ice-phase microphysical profiles }\end{array}$ & $13: 30$ & 2007-2011 \\
\hline TRMM* 3B42 (V7) & Precipitation rate & $12: 00$ & $2002-2013$ \\
\hline NOAA-NCEP GDAS & Meteorological fields & $11: 30$ & 2002-2013 \\
\hline CERES L3 (edition 3A) & TOA fluxes: SW $(0-5 \mu \mathrm{m})$ and LW $(5-100 \mu \mathrm{m})$ & $11: 30-14: 30$ & $2002-2013$ \\
\hline WMO station radiosondes & Temperature, relative humidity, dew point & $05: 30$ and $17: 30$ & $2002-2013$ \\
\hline
\end{tabular}

${ }^{*}$ Retrieved $0.25^{\circ}$ dataset re-gridded linearly to $1.0^{\circ}$ spatial resolution.

Here, we have used 12 years (JJAS) of gridded datasets of surface rainfall, aerosol, and cloud properties to examine aerosol-related changes in cloud macro-, micro-, and radiative properties and thereby in daily surface rainfall over the ISMR. Aerosol-associated changes in the onset of warm rain, microphysical profiles, and cloud radiative forcing are analyzed using observation and idealized simulations to investigate the significance of the aerosol microphysical effect over the ISMR. The role of meteorology and the aerosol humidification effect due to cloud contamination in retrieved AOD is also estimated to ensure the causality of the observed associations. This comprehensive effort to understand aerosolcloud-rainfall interactions over India will likely illustrate the significance of aerosols' impact on monsoonal rainfall via the microphysical pathway under continental conditions.

\section{Data and methodology}

\subsection{Aerosol, cloud, rainfall, and radiation datasets}

Table 1 summarizes in situ and satellite observations used in this study. For correlation analysis between aerosol-cloud macrophysics, we used retrievals of AOD, cloud fraction (CF), cloud top pressure (CTP), and cloud top temperature (CTT) from the Moderate Resolution Imaging Spectroradiometer (MODIS) onboard the Aqua spacecraft (Platnick et al., 2003; Remer et al., 2005). MODIS AOD has been validated extensively over land (Remer et al., 2005; Tripathi et al., 2005).

A new high-resolution $\left(0.25^{\circ} \times 0.25^{\circ}\right.$ gridded $)$ daily rainfall (RF) dataset prepared by India Meteorological Department (IMD) (Pai et al., 2013) was used to represent accumulated surface rainfall. Quality-ensured measurements of RF from in situ rain gauge stations $(\sim 6955)$ across the country were interpolated using an inverse distance-weighted interpolation scheme (Shepard, 1968) to create this gridded product. The daily surface rainfall from one day (08:30 LT) to 08:30 LT the next day has been recorded as daily rainfall at all rain gauge stations maintained by IMD for 110 years (1901-2013). This product has been extensively validated against previous IMD rainfall products as well as the Asian Precipitation - Highly-Resolved Observational Data Integration Towards Evaluation (APHRODITE) rainfall dataset (Pai et al., 2013). IMD daily rainfall gridded datasets have been widely used by several investigators to study the rainfall climatology and its inter-seasonal and intra-seasonal variability over the Indian summer monsoon region (Goswami et al., 2006; Krishnamurthy and Shukla, 2007, 2008; Pai et al., 2014; Rajeevan et al., 2008). The precipitation rate (PR) at 12:00 LT was also obtained from the Tropical Rainfall Measuring Mission (TRMM) (Huffman et al., 2010). RF as well as PR datasets were linearly re-gridded to the $1^{\circ} \times 1^{\circ}$ grid for consistency in our correlation analysis.

For the correlation analysis between any two variables, only those spatiotemporal grids were considered where collocated measurements of both variables were available. The collocated variables RF, PR, CF, CTP, and CTT were then sorted as a function of AOD and averaged to create a total of 50 scatter points. AODs $>1.0(\sim 5 \%)$ were omitted to reduce the possibility of the inclusion of cloud-contaminated data in our analysis. Shallow clouds with CTP $>850 \mathrm{hPa}$ (about $7 \%$ ) were also not considered in this analysis. Previous studies have also reported aerosol microphysical effects using such correlation analysis based on satellite datasets (Chakraborty et al., 2016; Feingold et al., 2001; Kaufman et al., 2002; Koren et al., 2010a, 2014, 2004, 2012; Myhre et al., 2007). Importantly, the availability of the ground-based in situ daily rainfall dataset enables us to further investigate the aerosol-cloud-rainfall association over the ISMR spanning from 17 to $27^{\circ} \mathrm{N}$ in latitude and 75 to $88^{\circ} \mathrm{E}$ in longitude (bounded by black box in Fig. 1). Here, we have excluded regions with mountainous terrain (Himalayan terrains to the north) and desert or barren land use regions (Thar Desert and nearby arid regions). This was done to avoid the inclusion of extreme orographic precipitation as well as retrieval error in the satellite products (e.g., lower sensitivity over brighter land surfaces for MODIS aerosol products). The ISMR has previously been extensively studied by several investigators (Bollasina et al., 2011; Goswami et al., 2006; Sengupta et al., 2013) as the rainfall variability over this re- 

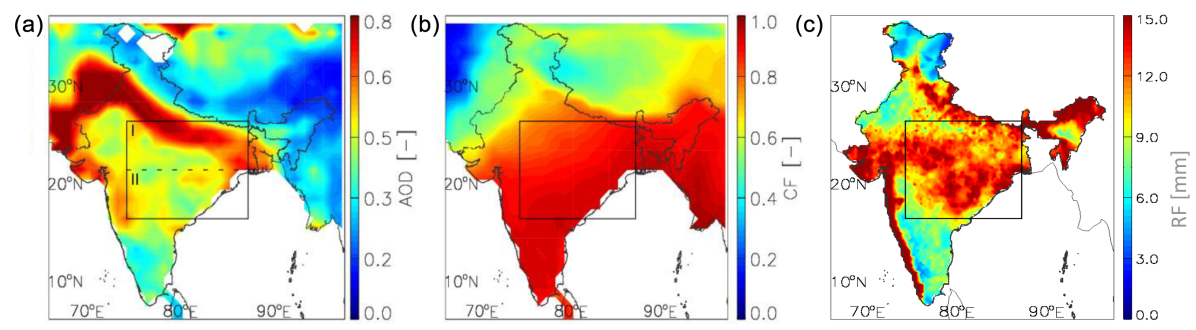

Figure 1. Climatological mean of (a) aerosol optical depth, (b) cloud fraction, and (c) daily rainfall for June through September 2002-2013. The black square box indicates the Indian summer monsoon region (ISMR) which is the focus of our analysis. Panel (a) illustrates the boundaries of regions I and II, used for sub-analysis (see the text).

gion is highly correlated with that of the entire Indian rainfall during June to September (Gadgil, 2003). Generally, aerosol loading over the ISMR is very high (climatological mean AOD of 0.56 , Fig. 1a), particularly over the densely populated Gangetic Basin. At the same time, the ISMR has a high cloud cover (CF of 0.72, Fig. 1b) and receives widespread rainfall (RF of $9.4 \mathrm{~mm}$, Fig. 1c) during the monsoon. This implies a rapid buildup of aerosol concentration over this region after every rainfall event, mainly due to a high emission rate and geography-induced accumulation of anthropogenic aerosols. Thus, the collocation of heavy pollution and abundant moisture over the ISMR makes it an ideal region to investigate aerosol-cloud-rainfall associations (Shrestha and Barros, 2010).

\subsection{Analysis of the aerosol impact on cloud radiative forcing}

Clouds increase Earth's albedo and cool the atmosphere by reflecting solar radiation to space; they also warm the atmosphere by absorbing Earth's outgoing longwave radiation (Trenberth et al., 2009). Thus, the aerosol microphysical effect in convective clouds will manifest itself in association between cloud radiative forcing and aerosol (Feingold et al., 2016; Koren et al., 2010b). Here, the Clouds and the Earth's Radiant Energy System (CERES) (Wielicki et al., 1996) retrieved outgoing shortwave (SW) and longwave (LW) radiation at the top of the atmosphere (TOA); this was also used to illustrate the aerosol-induced changes to cloud radiative forcing. The CERES fluxes were sorted and averaged as a function of AOD (similar to correlation analysis detailed in Sect. 2.1) for two different scenarios, i.e., all sky and clear sky. While aerosol radiative forcing during the clear-sky scenario includes only the aerosol direct effect, radiative forcing due to the aerosol indirect effect can be estimated from the net difference between the all-sky and the clear-sky scenario.

\subsection{Analysis of the aerosol impact on liquid- and ice-phase cloud microphysics}

MODIS observations of the cloud top liquid effective radius $\left(R_{\mathrm{e}}\right)$ as a function of cloud top pressure for convective cloud fields can be assumed as a composite $R_{\mathrm{e}}$-altitude profile obtained from tracking the space-time evolution of individual clouds (Lensky and Rosenfeld, 2006). The insensitivity of $R_{\mathrm{e}}$ to spatial variations at any particular altitude is also reported during the Cloud Aerosol Interaction and Precipitation Enhancement EXperiment (CAIPEEX) campaign over the ISMR (Prabha et al., 2011). CTP and $R_{\mathrm{e}}$ were segregated into groups of low (AOD $<33$ percentiles) and high (AOD $>67$ percentiles) aerosol loading regime using collocated AOD values. $R_{\mathrm{e}}$ as a function of CTP was compared between low- and high-aerosol regimes. The aerosol-associated differences in the growth of cloud droplets with height from these CTP- $R_{\mathrm{e}}$ profiles were used to infer aerosol-induced differences in warm cloud microphysical processes and the initiation of rain over the ISMR (Rosenfeld et al., 2014, and references therein).

CloudSat-retrieved profiles of liquid-phase and ice-phase water content as well as ice-phase effective radius $\left(R_{\mathrm{e}, \mathrm{ICE}}\right)$ available at $75 \mathrm{~m}$ vertical resolution within the ISMR (Austin et al., 2009; Stephens et al., 2002) were also segregated into low (AOD $<33$ percentiles) and high (AOD $>67$ percentiles) aerosol loading conditions. The mean microphysical variables along with their variability (profiles indicating 25th and 75th percentile) for low- and high-aerosol bins were plotted against altitude to visualize the net increase or decrease in liquid-phase water content, ice-phase water content, and the size of ice-phase hydrometeors at different altitudes with an increase in aerosol loading. The (two-sample) Student's $t$ test was used for statistical hypothesis testing about the mean of the groups in each subplot.

\subsection{Modeling aerosol-cloud-rainfall associations: a case study of a heavy-rainfall event over the ISMR}

The Weather Research and Forecasting (WRF) model is a regional numerical weather prediction system principally developed by the National Center for Atmospheric Research (NCAR) in collaboration with several research institutions in the USA. The Advanced Research WRF (ARW) version 3.6 along with a newly coupled, fast version of spectral bin microphysics (WRF-SBM) is used to perform three idealized supercell simulations of a typical heavy-rainfall event over 
the ISMR. The spectral bin microphysics scheme is specially designed to study the aerosol effect on cloud microphysics, dynamics, and precipitation based on solving a kinetic equations system for size distribution functions described using 33 doubling mass bins (Khain and Lynn, 2009; Khain et al., 2004; Lynn and Khain, 2007). In fast SBM four size distributions are solved, one each for $\mathrm{CCN}$, water drops, lowdensity ice particles, and high-density ice particles. All ice crystals (sizes $<150 \mu \mathrm{m}$ ) and snow (sizes $<150 \mu \mathrm{m}$ ) are calculated in the low-density ice particle size distribution. Graupel and hail are grouped with high-density ice, represented with one size distribution without separation. The empirical dependence $N=N_{o} \times S^{k}$ is used to calculated the initial (at time, $t=0$ ) CCN size distribution (see Khain et al., 2000, for details), where $N_{o}$ and $k$ are parameters which vary with aerosol number concentration and chemical composition, respectively, and $N$ is the concentration of nucleated droplets at supersaturation, $S$ (in \%) with respect to water. At each time step the critical aerosol activation diameter of cloud droplets is calculated from the value of $S$ (using Kohler theory). It explicitly calculates the nucleation of droplets and ice crystals, droplet freezing, condensation, coalescence growth, deposition growth, evaporation, sublimation, riming, melting, and breakup of the categorized hydrometeor particles. Details about the parameterizations used for these processes can be found in previous studies (Khain and Lynn, 2009; Khain et al., 2004; Lynn and Khain, 2007).

We found that the mean relative humidity in the lower troposphere remains high over the ISMR during moderateand heavy-rainfall events $(\mathrm{RF}>6 \mathrm{~mm})$ using the Global Data Assimilation System (GDAS) data (figure not shown). Our simulations were initiated with morning radiosonde measurements (on 23 August 2009) from the Patna station of the India Meteorological Department (Fig. 2). A mesoscale convective system was prevalent over Patna during 22-25 August 2009. The moisture mixing ratio was high in the lower troposphere during this event (Fig. 2) which is typical of a moderate- to heavy-rainfall event over the ISMR. This particular period was selected because measurements of the $\mathrm{CCN}$ spectrum near the cloud base were also available from the CAIPEEX campaign over the region (Prabha et al., 2012). We performed three simulations with the same initial thermodynamic conditions but different initial $N_{o}$ to represent low $\left(N_{o}=\right.$ 4500 particles $\left.\mathrm{cm}^{-3}\right)$, medium $\left(N_{o}=9000\right.$ particles $\left.\mathrm{cm}^{-3}\right)$, and heavy $\left(N_{o}=15500\right.$ particles $\left.\mathrm{cm}^{-3}\right)$ aerosol loading conditions, hereafter referred to as Ex1, Ex2, and Ex3, respectively. The simulations were performed for $160 \mathrm{~min}$ at a resolution of $1 \mathrm{~km}$ over a domain of $300 \mathrm{~km} \times 300 \mathrm{~km}$. The number of vertical sigma levels was 41 , and the top height was about $20 \mathrm{~km}$. Rayleigh damping was used to damp the fluctuations reaching the upper troposphere in the idealized simulation (Khain et al., 2005). An exponentially decreasing (both horizontally and vertically) temperature pulse of $3{ }^{\circ} \mathrm{C}$ was used to trigger the storm (Khain and Lynn, 2009;

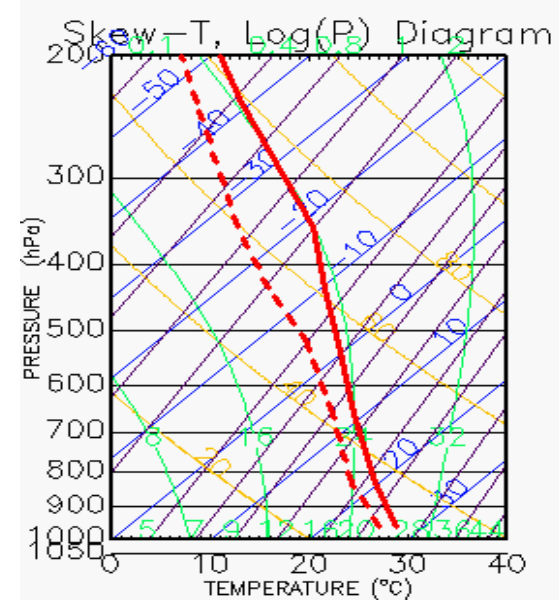

Figure 2. Skew-T - log-P diagram illustrating the initial conditions of dew point temperature (red hashed line) and atmospheric temperature (red solid line) used in all the three WRF-SBM idealized simulations. Blue, yellow, green, black, and purple lines indicate lines of constant temperature (isotherm), potential temperature, and equivalent potential temperature, pressure (isobar), and saturation mixing ratio, respectively.

Khain et al., 2004; Lynn and Khain, 2007). A comparison of droplet size distribution, microphysical profiles, vertical velocity, column-accumulated water content of various cloud species, and surface rainfall from these simulations illustrates the process-level linkage between aerosol increase and surface rainfall. The simulation output of mass-size distributions of water droplets, low-density ice particles, and high-density ice particles was recorded every $15 \mathrm{~min}$ of model time. Assuming that all the hydrometeors were spherically shaped, we calculated the number-size distribution from the masssize distribution by using the bulk radius-density functions specified in SBM for each hydrometeor (shown in Fig. 1 of Iguchi et al., 2012). The bulk effective radius $\left(R_{\mathrm{e}}\right)$ of each size distribution was calculated as shown in Eq. (1) below:

$R_{\mathrm{e}}=\frac{\sum_{i=3}^{33} r_{i}^{3} N_{i}}{\sum_{i=3}^{33} r_{i}^{2} N_{i}}$,

where $r_{i}$ is half of the maximum diameter and $N_{i}$ is the particle number concentrations of the $i$ th bin. For calculating the $R_{\mathrm{e}}$ of cloud droplets the bins with diameter $<50 \mu \mathrm{m}$ was considered. We used the 1 st -17 th bins and the 17 th -33 th bins of the low-density ice hydrometeors size distribution, separately, to calculate $R_{\mathrm{e}}$, ice and $R_{\mathrm{e} \text {, snow }}$, respectively. $R_{\mathrm{e} \text {, graupel }}$ was calculated using the size distribution of high-density ice particles. 


\subsection{Analysis of possible caveats in correlation analysis}

It is well documented that the aerosol-cloud correlation analysis using satellite data can be affected by one or more of the following factors: (1) positive correlation of variability in aerosol and cloud-rainfall fields with meteorological variations, which are the true modifiers of cloud and rainfall properties (Chakraborty et al., 2016; Kourtidis et al., 2015; Ten Hoeve et al., 2011), (2) cloud contamination of retrieved AOD values due to the aerosol humidification effect (Boucher and Quaas, 2013; Gryspeerdt et al., 2014), and (3) inaccurate representation of the wet-scavenging effect in the satellite-retrieved AOD dataset (Grandey et al., 2013, 2014; Yang et al., 2016). Therefore, we have critically investigated the plausible role of these factors in our analyses as presented below.

\subsubsection{The influence of meteorological variability}

Here, we obtained various meteorological fields from the NOAA-NCEP (National Oceanic and Atmospheric Administration National Centers for Environmental Prediction) GDAS dataset (Parrish and Derber, 1992) as an approximation for the meteorological conditions at the same time and location as the satellite observations. Since the NOAA-NCEP GDAS assimilated product does not contain direct information on the aerosol microphysical effects, it is a suitable tool to investigate whether the meteorological variations favored aerosol accumulation under wet or cloudy conditions (Koren et al., 2010a). GDAS variables at $1^{\circ}$ spatial resolution and 21 vertical model levels $(1000-100 \mathrm{hPa})$ over the ISMR from the 12:00 LT run were used. First, the correlation of different GDAS meteorological variables with cloud fraction, daily rainfall, and AOD, separately, using all grid points within the ISMR at each model vertical level was performed. Based on the correlation analysis, the likely meteorological variables (with correlation coefficient $>0.25$ ) which can affect cloud and rainfall properties in the ISMR were identified. Next, we made narrow regimes of these key meteorological variables to constrain the variability in these meteorological factors and repeated the correlation analysis of AOD-cloud-rainfall gradients. This approach can be assumed to be similar to simulating the effect of increasing aerosol loading on the cloudrainfall system for similar meteorology

\subsubsection{Cloud contamination of aerosol retrievals}

Aerosol-cloud-rainfall studies based on satellite data are, in part, biased by the aerosol humidification effect due to uncertainties in retrieved AOD from near-cloud pixels. For instance, an increase in the surface area of aerosols due to water uptake may cause elevated AOD levels measured in the vicinity of clouds (Boucher and Quaas, 2013). The humidification effect on the AOD depends on the variability range of ambient relative humidity (RH; Altaratz et al., 2013). Here, we used radiosonde measurements (JJAS, 2002 to 2013) from World Metrological Organization stations (Durre et al., 2006), within the ISMR (Table 2) to identify profiles that had the potential of cloud formation. Specifically, the selected profiles had an unstable layer below the lifting condensation level (LCL). However, the profiles suggesting low-level clouds (mean RH below LCL > $98 \%$ ) were removed. A major portion of aerosols contributing to columnar AOD is usually present below $3 \mathrm{~km}$ altitude over the ISMR during monsoon or cloudy conditions. Thus, we focused this analysis on $\mathrm{RH}$ below $3 \mathrm{~km}$ altitude. Also, the changes in mean $\mathrm{RH}$ values associated with the change in cloud vertical extent was calculated based on Altaratz et al. (2013). The height above the level of free convection where the theoretical temperature of a buoyantly rising moist parcel (following wet adiabatic lapse rate) becomes equal to the temperature of the environment is referred to as the equilibrium level. The height of atmospheric layer between LCL and the equilibrium level is referred to as the cloudy layer height (CLH). Also, in the case of the presence of inversion layer, the top of the CLH is determined as the base of the lowest inversion layer located above the LCL. Based on median CLH, the selected profiles at each station were divided into two subsets of an equal number of samples representing shallower and deeper clouds. The bias in mean RH between shallower and deeper clouds for each station was calculated to illustrate the influence of cloud height on the RH variability.

Bar-Or et al. (2012) have parameterized RH in cloudy atmosphere as a function of the distance from the nearest cloud edges. Given the hygroscopic parameter, $k$, this parameterization can be used to simulate hygroscopic properties and model the humidified aerosol optical depth. Bhattu and Tripathi (2014) have reported that $k$ of ambient aerosol over Kanpur (in the Gangetic Basin) during the monsoon is $0.14 \pm 0.06$. Accordingly, we have considered minimum (maximum) $k$ over the ISMR as $0.1(0.2)$, and have used the parameterization to estimate the change in AOD due to the observed variation in the RH field. First, the range in $\mathrm{RH}$ variation was scaled as the distance from the nearest cloud (using Fig. 3 of Bar-Or et al., 2012), and then the change in AOD was estimated (using Fig. 6 of Bar-Or et al., 2012) for each subset.

\subsubsection{The effect of underrepresentation of the wet-scavenging effect on retrieved AOD values}

Aerosols present below cloudy pixels are not visible to satellite. To circumvent this limitation in investigating aerosolcloud-rainfall association, it can be reasonable to assume that the mean aerosol distribution below the non-raining cloudy pixels is similar in magnitude to the aerosol distribution of the non-cloudy pixels within a $1^{\circ} \times 1^{\circ}$ grid box. Nevertheless, aerosols below cloudy pixels where rainfall occurs are subject to depletion due to the wet-scavenging effect. Thus, the wet-scavenging effect might not be accu- 
Table 2. World Meteorological Organization (WMO) index number of radiosonde stations (WMO no.), station latitude (lat), longitude (long), elevation above mean sea level (elev.), number of radiosonde profiles $(N)$, number of cloudy profiles $\left(N_{\text {cloudy }}\right)$, mean RH (relative humidity), and bias in $\mathrm{RH}$ for $1.5 \mathrm{~km}$ layer $\left(\mathrm{RH}_{1.5}\right.$ and $\mathrm{RH}_{1.5 \text {, bias }}$, respectively.) and $3.0 \mathrm{~km}$ layer $\left(\mathrm{RH}_{3.0}\right.$ and $\mathrm{RH}_{3.0 \text {, bias }}$, respectively), and median of cloud layer height $(\mathrm{CLH})$ for each of the eight radiosonde stations used in the humidification analysis. The symbol " \pm " indicates standard deviation.

\begin{tabular}{lrrrrrrrr}
\hline Station & Vishakhapatnam & Kolkata & Bhubaneswar & Patna & Lucknow & Nagpur & Bhopal & Ranchi \\
\hline WMO no. & 43150 & 42809 & 42971 & 42492 & 42369 & 42867 & 42667 & 42701 \\
Lat $\left(^{\circ} \mathrm{N}\right)$ & 17.43 & 22.39 & 20.15 & 25.36 & 26.45 & 21.06 & 23.17 & 23.19 \\
Long ( ${ }^{\circ}$ E) & 83.14 & 88.27 & 85.50 & 85.06 & 80.53 & 79.03 & 77.21 & 85.19 \\
Elev. (m) & 3 & 6 & 46 & 60 & 128 & 310 & 523 & 652 \\
$N$ (no.) & 2007 & 2291 & 2306 & 1432 & 1751 & 1916 & 1725 & 1616 \\
$N_{\text {cloudy }}$ (no.) & 770 & 1065 & 823 & 709 & 837 & 898 & 555 & 270 \\
$\mathrm{RH}_{1.5}$ & $83 \pm 12$ & $88 \pm 11$ & $89 \pm 11$ & $88 \pm 11$ & $83 \pm 15$ & $82 \pm 16$ & $83 \pm 16$ & $89 \pm 12$ \\
$\mathrm{RH}_{1.5}$, bias & 1.96 & 0.95 & 1.5 & 0.6 & 6.1 & 3.8 & 6.4 & 1.4 \\
$\mathrm{RH}_{3.0}$ & $82 \pm 12$ & $86 \pm 14$ & $88 \pm 12$ & $87 \pm 13$ & $84 \pm 15$ & $84 \pm 15$ & $84 \pm 16$ & $87 \pm 14$ \\
$\mathrm{RH}_{3.0, \text { bias }}$ & 0.5 & 1.5 & 0.8 & 1.4 & 5.1 & 3.8 & 6.4 & 0.3 \\
$\mathrm{CLH}_{\text {(m) }}$ & 13810 & 14539 & 14455 & 14413 & 13430 & 9658 & 6343 & 9219 \\
\hline
\end{tabular}

rately represented in the MODIS-retrieved AOD dataset used in our study. Modeling studies suggest that this artifact in the satellite-retrieved AOD values can significantly affect the magnitude as well as the sign of the aerosol-cloud-rainfall associations (Grandey et al., 2013, 2014; Yang et al., 2016). At the same time, Gryspeerdt et al. (2015) have recently illustrated that the aerosol in neighboring cloud-free regions may be more representative for aerosol-cloud interaction studies than the below-cloud aerosol using a high-resolution regional model; this justifies the methodology used in their study. The main limitation in investigating the impact of probable inaccuracy in representing the wet-scavenging effect on our analysis is a lack of collocated measurements of aerosol, cloud, and rainfall at a temporal resolution of rainfall events from space-borne measurements. Hence, we used collocated hourly measurements of aerosol and rainfall over the Indian Institute of Technology, Kanpur, (IITK) as a representative case study dataset to investigate the possible effect of wet scavenging on aerosol-rainfall associations within the ISMR.

The AErosol RObotic NETwork (AERONET) is a global network of ground-based remote-sensing stations that provides quality-controlled measurements of aerosol optical depth with a high accuracy (Dubovik and King, 2000; Holben et al., 1998). Hourly averages of AOD $(550 \mathrm{~nm})$ used in this analysis were obtained from the quality-ensured Level-2 product of the AERONET site on the IITK campus. Rainfall events were identified from collocated rain gauge measurements near the AERONET station within the IITK campus between April-October 2006-2015. We included the months of April, May, and October to increase the number of sample points. The rainfall amount of all the rainfall events was sorted as a function of collocated AERONET-AOD values (mean of AERONET-AOD measurements within $\pm 4 \mathrm{~h}$ of the start/end of the rainfall) into five equal bins of 20 percentiles each. As AERONET-AOD measurements were available only between sunrise and sunset, we used AOD values of late evening measurements as representative of aerosol loading during the first rainfall event (if any) at nighttime. However, in the case of more than one rainfall event at night, only the first rainfall event is considered in this analysis. Nearly half of the AOD-rainfall samples used here included AOD measurements within $4 \mathrm{~h}$ after the end of any rainfall event, and, therefore, this includes a wet-scavenging effect of rainfall on AOD measurements. To reproduce another specific scenario, only the rainfall-AOD samples when AOD measurement was available before the start of rainfall events were collected and sorted as a function of AOD into five equal bins of 20 percentiles each. This restricted sampling does not include the wet-scavenging effect as only the AODvalues before the start of rainfall in each rainfall event were used. The average rainfall amount for each bin was plotted against mean AOD values under both scenarios to illustrate the difference in aerosol-rainfall association due to the exclusion of the wet-scavenging effect within the ISMR.

\section{Results and discussion}

\subsection{Cloud, rainfall, and radiation associations with aerosol loading}

Figure 3a shows the relationship between AOD and IMD RF. $\mathrm{RF}$ increased from 5.9 to $7.1 \mathrm{~mm}$ as AOD increased from 0.25 to 0.75 . A similar relationship was also observed in the case of TRMM PR in Fig. 3b. The precipitation rate increased from 0.31 to $0.38 \mathrm{~mm} \mathrm{~h}^{-1}$ for the same amount of increase in AOD (0.25 to 0.75). A concurrent analysis of aerosol and cloud properties showed aerosol-induced modifications in cloud macrophysics. Widening of clouds was observed as cloud fraction increased from 0.78 to 0.92 with an increase in AOD from 0.25 to 0.75 (Fig. 3c). A mono- 

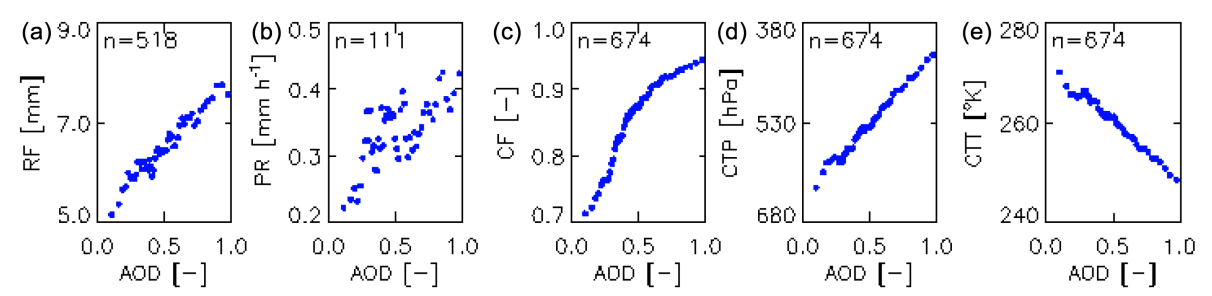

Figure 3. Associations of (a) daily rainfall, (b) precipitation rate, (c) cloud fraction, (d) cloud top pressure, and (e) cloud top temperature with AOD. The collocated data points for these five variables (a-e) were sorted as a function of AOD over the ISMR during JJAS $2002-2013$. The total number of collocated data points $(50 \times n)$ is then used to create 50 AOD bins of " $n$ " number of samples ( 2 percentiles) each. Each scatter point is the average of these equal " $n$ " numbers of data points mentioned in each respective panel.

tonic decrease in CTP and CTT (Fig. 3d and e), by nearly $200 \mathrm{hPa}$ and $22 \mathrm{~K}$, respectively, for the same increment in AOD further indicates vertical deepening of the cloud with increasing aerosol loading. Aerosol-cloud studies have reported a reduction in cloudiness under high AOD for regions with high absorbing aerosol loading (Koren et al., 2004; Small et al., 2011). Widespread cloud coverage over the ISMR ( $\mathrm{CF}$ of $\sim 0.75$ for AOD $\sim 0.3$ in Fig. 3 ) induces a substantial reduction in the incoming solar radiation (Padma Kumari and Goswami, 2010), which may result in reduced interaction between absorbing aerosols and shortwave radiation. This explains that, despite the high emission rate of absorbing aerosols over the ISMR (Bond et al., 2004), the aerosol-induced cloud inhibition effect seemed to have been reduced to a second-order process during the Indian summer monsoon. For a sanity check, we have reanalyzed cloud and rainfall associations with aerosol loading by dividing the ISMR into two subregions (shown in Fig. 1a). Similar aerosol-cloud-rainfall associations (in both the regions) were observed to that seen in Fig. 3. In addition, the analysis was also repeated by segregating the dataset into low-level $(850 \mathrm{hPa}>\mathrm{CTP}>500 \mathrm{hPa})$ and high-level clouds $(\mathrm{CTP}<500 \mathrm{hPa})$ (figure not shown). Despite the considerable differences in mean CTP and CTT found between lowand high-level clouds, the general associations were similar in both the regimes (as in Fig. 3). An analysis of individual months, viz June, July, August, and September, also illustrated similar positive associations as seen in Fig. 3, indicating negligible intra-seasonality in the observed associations.

The observed associations in Fig. 3 are in line with the recent aerosol-cloud-rainfall association studies under continental conditions (Kourtidis et al., 2015; Myhre et al., 2007; Ten Hoeve et al., 2011), CTP (Li et al., 2011; Myhre et al., 2007; Yan et al., 2014), and rainfall (Gonçalves et al., 2015; Heiblum et al., 2012). These studies suggested that aerosolinduced changes in cloud dynamics and microphysics are the potential causal mechanism for the aerosol-cloud-rainfall linear dependence. Over the Indian region, previous studies have compared MODIS-observed cloud microphysical properties between low- and high-aerosol loading to demonstrate the aerosol microphysical effect and its linkage to interan- nual variations in seasonal rainfall (Abish and Mohanakumar, 2011; Panicker et al., 2010; Ramachandran and Kedia, 2013). Aerosol impacts on cloud microphysics over central India based on ground-based measurements are also evident (Harikishan et al., 2016; Tripathi et al., 2007). Aircraft measurements during the CAIPEEX campaign over the ISMR have provided unprecedented evidence of the aerosol microphysical effect on cloud droplet distribution and warm rainfall suppression over the ISMR (Konwar et al., 2012; Pandithurai et al., 2012; Prabha et al., 2011). Recently, Sengupta et al. (2013) have also discussed the possible aerosol-induced deepening of clouds with the evolution of the Indian monsoon using MODIS-retrieved CTP.

Next, aerosol-related convective invigoration was investigated using CERES-retrieved outgoing radiative fluxes at the top of the atmosphere. Our analyses showed that for every unit increase in AOD, reflected SW radiation increased by $\sim 68 \mathrm{~W} \mathrm{~m}^{-2}$, whereas LW decreased by $\sim 26 \mathrm{~W} \mathrm{~m}^{-2}$ at the top of the atmosphere for the all-sky scenario (Fig. 4a). Taller clouds exhibit colder cloud tops as they are in a thermodynamic balance with the environment, therefore, the observed decrease in LW with an increase in AOD further provides evidence of aerosol-induced cloud invigoration over the ISMR (Koren et al., 2014, 2010b). Increased cloudiness was also evidenced as the cloud albedo increased, thereby reflecting back more SW radiation at the top of the atmosphere. A large number of small ice crystals formed in the upper troposphere due to cloud invigoration eventually become aligned as larger and longer-lived anvils detrained from cloud tops (Fan et al., 2013). Such an anvil expansion effect of aerosol (Rosenfeld et al., 2014) may also contribute to the aerosolassociated increase in SW radiative forcing. Quantitatively, the net cooling per unit increase in AOD (Fig. 4b) under the clear-sky scenario was $\sim 1326 \mathrm{~W} \mathrm{~m}^{-2}$, whereas the net cooling for same change in AOD under cloudy conditions was twice more than that under the clear-sky scenario i.e., $\sim 30 \mathrm{~W} \mathrm{~m}^{-2}$. 

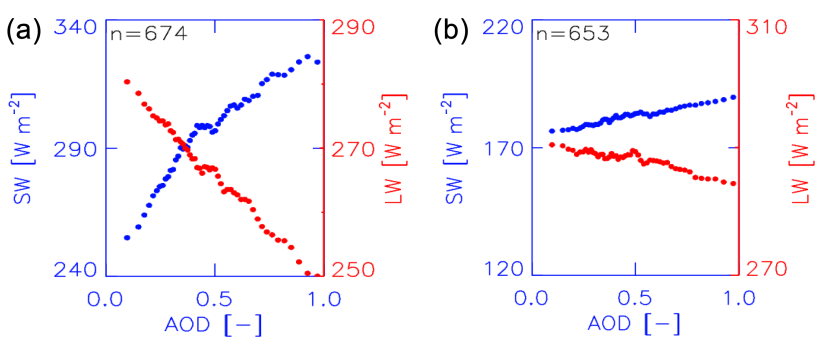

Figure 4. Association of CERES-retrieved incoming shortwave (SW) and outgoing longwave (LW) radiation with AOD for (a) the all-sky and (b) the clear-sky scenario over the ISMR during JJAS 2002-2013. The collocated data points for both SW and LW as a function of AOD were first sorted. The total number of collocated data points $(50 \times n)$ is then used to create 50 AOD bins of " $n$ " number of samples ( 2 percentiles) each. Each scatter point is the average of these equal " $n$ " numbers of data points mentioned in each respective panel.

\subsection{Aerosol-induced cloud invigoration}

\subsubsection{The effect of aerosol-related changes in microphysical processes}

Many studies have shown that the onset of warm rain and collision-coalescence processes is dependent on the $\mathrm{CCN}$ concentration (Freud et al., 2011, and references therein). The MODIS-retrieved droplet effective radius as a function of CTP grouped under low and high aerosol loading cases can be used to investigate the aerosol-induced differences in warm rain processes like diffusion and coalescence processes (Rosenfeld et al., 2014). In Fig. 5, we present cloud microphysical changes for low and high aerosol loading using MODIS and CloudSat datasets.

Figure 5a illustrates that $R_{\mathrm{e}}$ of liquid droplets near the cloud base was smaller $(6 \mu \mathrm{m})$ in clouds developed under higher AOD conditions, which is in agreement with the aerosol first indirect effect (Twomey, 1974). In addition, the vertical growth of $R_{\mathrm{e}}$ under polluted conditions increased at a gradual rate $\left(\sim 3 \mu \mathrm{m}(100 \mathrm{hPa})^{-1}\right)$ for $R_{\mathrm{e}}<14 \mu \mathrm{m}$ compared to the vertical gradient of increase in $R_{\mathrm{e}}\left(\sim 10 \mu \mathrm{m}(100 \mathrm{hPa})^{-1}\right)$ in relatively clean clouds (low aerosol loading). Also note that the altitude difference between the cloud base and the onset of warm rain was smaller under low-AOD cases $(\sim 50 \mathrm{hPa})$ compared to that in highAOD cases $(\sim 250 \mathrm{hPa})$. Concurrently, the mean $R_{\mathrm{e}}$ for highAOD cases was very small $(\sim 10 \mu \mathrm{m})$ near the freezing level compared to low AOD, indicating an increase in droplets of a smaller size at higher levels with an increase in aerosol loading (Fig. 5a). Thus, a significant increase in and sustenance of smaller supercooled liquid drops was found above freezing level under polluted conditions. Aircraft measurements of clouds developed under dirty conditions during the CAIPEEX campaign over the ISMR have also documented that $R_{\mathrm{e}}$ remained below $14 \mu \mathrm{m}$ up to $500 \mathrm{hPa}$ altitude, and the formation of rain drops was mainly initiated as supercooled raindrops at $\sim 400 \mathrm{hPa}$ (Konwar et al., 2012; Prabha et al., 2011).

From CloudSat analyses, the mean ice-phase effective radius $\left(R_{\mathrm{e}, \mathrm{ICE}}\right)$ for high aerosol loading was found to be $8-10 \%$ greater (significant at $>95 \%$ confidence interval) throughout the cloud layer compared to that for low aerosol loading at the same altitude (Fig. 5b), indicative of the formation of larger-sized ice-phase hydrometeors under high aerosol loading. Figure 5c shows the difference (high aerosol-low aerosol) in mean liquid-phase and ice-phase water content. Significant enhancements in ice-phase water content were clearly evident under high aerosol loading (Fig. 5c). The increase in the mass concentration of ice-phase hydrometeors was $\sim 50 \mathrm{mg} \mathrm{m}^{-3}$ at altitudes of $8-13 \mathrm{~km}$. A similar increase in the number concentration of ice hydrometeors was also observed from CloudSat observations (figure not shown).

\subsubsection{Modeling the aerosol microphysical effect for a typical rainfall event during ISM}

In order to further investigate the process-level insights to our observational findings, we conducted model simulations using WRF-SBM for a typical mesoscale convective system over the ISMR. Three idealized supercell simulations (Ex1, Ex2, and Ex3, as explained above) were performed, with the observed CCN spectra being lowest for Ex1 and highest for Ex3.

Figure 6a shows the time evolution of domain-averaged mean columnar cloud water content (CWC), rain water content (RWC), summation of ice-phase hydrometeors, i.e., snow, graupel, and ice water content (SWC + GWC + IWC), vertical velocity $(W)$, and accumulated rainfall for low-CCN (aerosol) conditions. It can be seen that convection was strong after $50 \mathrm{~min}$ (consistent updrafts $>0.2 \mathrm{~m} \mathrm{~s}^{-1}$ ), with corresponding enhancements in CWC, RWC, and hydrometeors until the end of the simulation. The domain-averaged accumulated rainfall was found to be $\sim 0.8 \mathrm{~mm} \mathrm{grid}^{-1}$ at the end of the simulation. The simulated differences between high-CCN and low-CCN conditions (Fig. $6 \mathrm{~b}$ and c) clearly shows significant intensification in the microphysical and dynamic variables with an increase in $\mathrm{CCN}$ concentration. The magnitude of $W, \mathrm{CWC}$, RWC, and ice-phase water content increased in both simulations (Ex2 and Ex3) compared to simulation Ex1. The simultaneous increase in accumulated rainfall was also evident with an increase in $\mathrm{CCN}$ concentrations, mainly during the last half of the simulations. The estimated AOD for prescribed CCN scenarios in Ex1, Ex2, and Ex3 at $0.4 \%$ supersaturation is $0.42,0.62$, and 0.91 , respectively (using the empirical formula given by Andreae, 2009). The observed increase in accumulated rainfall was found to be 0.68 and $0.28 \mathrm{~mm}$ for an increase in AOD of 0.5 (Ex3Ex1) and 0.3 (Ex2-Ex1), respectively, suggesting a nearly linear relationship in $\mathrm{CCN}$-cloud-rainfall association as ob- 

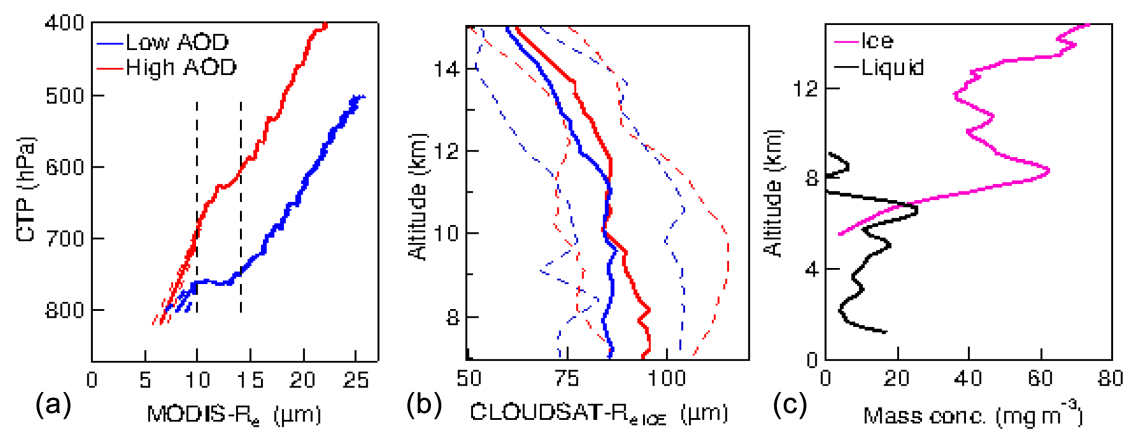

Figure 5. Observed differences in cloud microphysical properties for low and high aerosol loadings cases. (a) MODIS-observed mean profiles of liquid-phase effective radius $\left(R_{\mathrm{e}}\right)$; (b) CloudSat-observed mean profiles of ice-phase effective radius $\left(R_{\mathrm{e}}\right.$, ICE) under low (blue) and high (red) aerosol loading conditions. The dotted lines represent 25th and 75th percentiles, respectively. (c) Difference (high AOD-low AOD) in mean profiles of liquid-phase (black) and ice-phase (pink) water content as observed from CloudSat.

served in Fig. 2. Nevertheless, a closer look at Fig. 6b and c reveal a temporal delay in the initial formation of RWC, icephase hydrometeors, and surface rainfall with an increase in $\mathrm{CCN}$ concentrations. This can be understood from the negative values of differences in RWC, total water content of ice-phase hydrometeors, and rainfall between 40-100 min of the simulation. However, the increase in rainfall amount with an increase in $\mathrm{CCN}$ concentration at a later stage of the simulation was manifold compared to the initial suppression of warm rainfall eventually leading to the enhancement of accumulated rainfall throughout the storm domain (figure not shown).

Figure $7 \mathrm{a}$ illustrates the simulated time- and domainaveraged profiles of the droplet effective radius for Ex 1 and Ex3. It can be seen that droplet $R_{\mathrm{e}}$ in the Ex3 simulation was lower compared to that of Ex1 throughout the cloud column and the differences increased with altitude, indicative of the slower growth of cloud droplets for high-CCN conditions (Ex3) as compared to low CCN (Ex1), in line with our observation from MODIS analyses. For instance, the difference in droplets at 700 and $300 \mathrm{hPa}$ was $\sim 3$ and $\sim 8 \mu \mathrm{m}$, respectively (Fig. 7b). The simulated spectral width of the droplet size distributions for Ex 3 and Ex 1 also showed a significant shift of the droplet spectra toward lower $R_{\mathrm{e}}$ with an increase in $\mathrm{CCN}$. It can be seen that an increase in $\mathrm{CCN}$ concentration also leads to a narrowing of the droplet spectra at the same altitude.

The aerosol-induced increase (Ex3-Ex1) in time- and domain-averaged CWC, RWC, IWC, SWC, and GWC at different altitudes is shown in Fig. 8a. Modeling results also show that the maximum increase in CWC $\left(23 \mathrm{mg} \mathrm{m}^{-3}\right)$ was above freezing level at an altitude of $\sim 7 \mathrm{~km}$, which suggests that the increase in $\mathrm{CCN}$ caused an increase in supercooled liquid droplets. Similar plots of mean $W$ and temperature differences averaged over cloudy pixels (Fig. 8b) show a considerable increase in temperature and $W$ at altitudes corresponding to an increase in CWC (i.e., below $8 \mathrm{~km}$ ), mainly due to an enhanced release of latent heat of condensation.
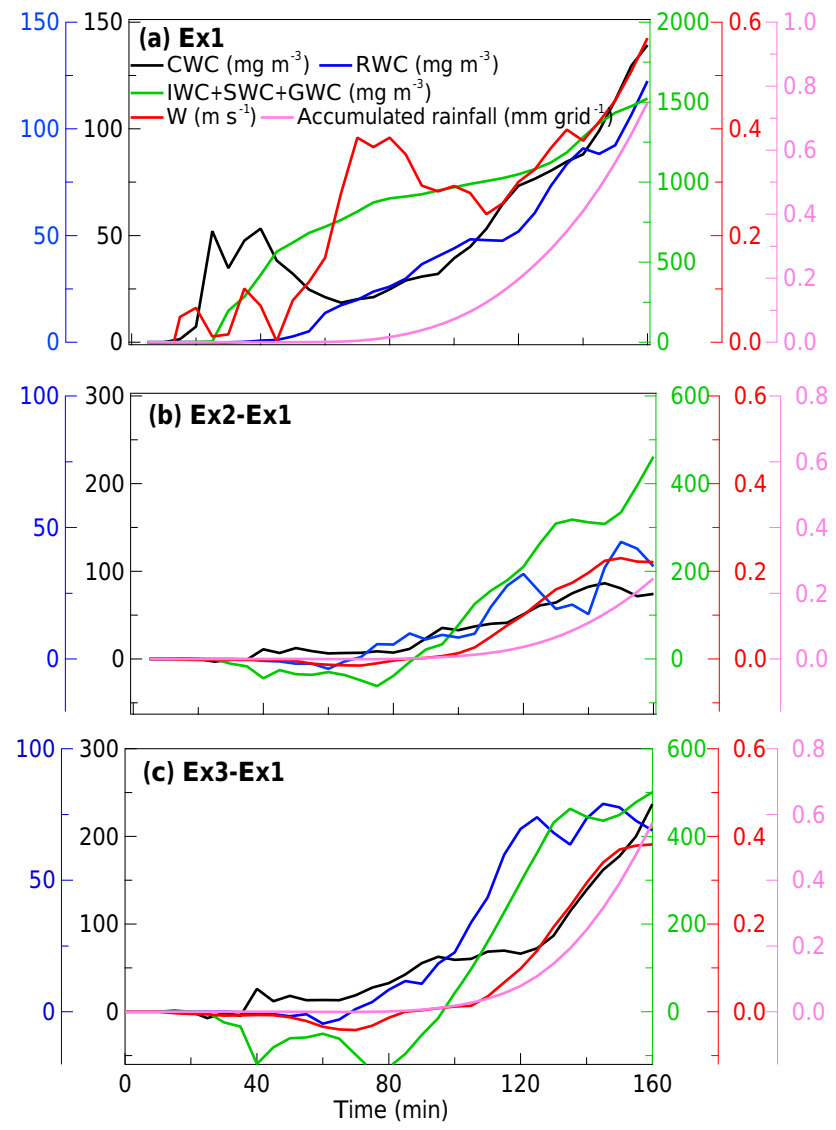

Figure 6. (a) Time evolution of column-integrated domainaveraged cloud water content (CWC; black), rain water content (RWC; blue), summation of ice water content, graupel water content, and snow water content (IWC $+\mathrm{GWC}+\mathrm{SWC}$; green), vertical velocity (red), and accumulated surface rainfall (pink) for simulation Ex1. (b) Same as panel (a), but for simulated differences between Ex2 and Ex1. (c) Same as panel (a), but for simulated differences between Ex3 and Ex1. 

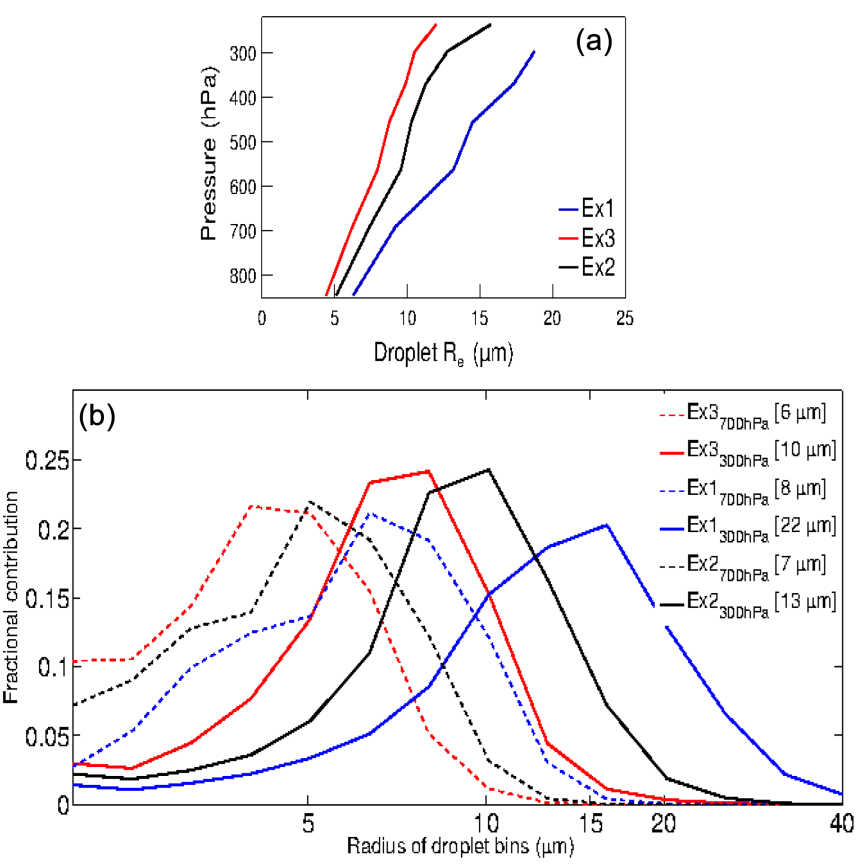

Figure 7. (a) Mean droplet $R_{\mathrm{e}}$ versus CTP for low- (Ex1; blue), medium- (Ex2; black), and high- (Ex3; red) CCN scenario. (b) Droplet size distribution spectra of Ex1 (blue), Ex2 (black), and Ex3 (red) simulations at $700 \mathrm{hPa}$ (dashed lines) and $300 \mathrm{hPa}$ (solid lines). The corresponding effective radius values are mentioned in the legends in square brackets. The fractional contribution is calculated by dividing the mass concentration of each bin with the total mass concentration.

For ice-phase hydrometeors, the majority of the increase was observed in SWC, with a peak above $\sim 12 \mathrm{~km}$ altitude. A maximum in the $\mathrm{CCN}$-induced increase in vertical velocity and temperature was also found to be above $\sim 12 \mathrm{~km}$ (Fig. 8). These results indicate that a $\mathrm{CCN}$-induced increase in the latent heat of freezing occurred mainly above $12 \mathrm{~km}$, in turn strengthening the updraft velocity of cloud parcels and hydrometeor formation. Further, snow $R_{\mathrm{e}}$ profiles for simulations Ex 1 and Ex3 illustrated that the effective mean radius of snow significantly increased with an increase in CCN concentration between 8 and $15 \mathrm{~km}$ altitude (Fig. 9a). The simulated particle size distribution of snow further explained this behavior as the mass of particles in larger-sized bins increased in the simulation Ex3 compared to Ex1 (Fig. 9b). Similar changes in graupel concentration and particle size distribution for high-density ice particles were also found (figure not shown).

It has to be noted that the $\mathrm{CCN}$-induced differences in cloud microphysics and rainfall from this idealized case study simulation should not be directly compared with the decadal-scale observational analysis. Moreover, these results are subject to various assumptions and uncertainties within physical parameterizations of the microphysics module used. However, the qualitative similarities in results between the
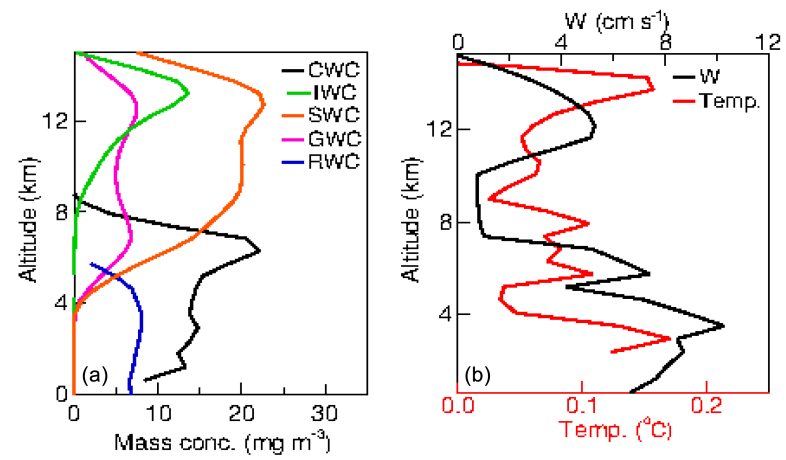

Figure 8. (a) Simulated difference (Ex3-Ex1) in mean profiles of cloud water content, rain water content, ice water content, graupel water content, and snow water content. (b) $\mathrm{CCN}$-induced difference (Ex3-Ex1) in simulated mean profiles of vertical velocity (black) and temperature (red) for cloudy pixels.

observed aerosol-cloud-rainfall associations and this idealized case study simulation provide confidence in our observational finding that aerosol loading can potentially alter the warm phase and cloud phase microphysics over the ISMR. These perturbations are consistent with processes typically associated with aerosol-induced cloud invigoration (Altaratz et al., 2014; Tao et al., 2012).

The following chain of processes may explain our observational and/or numerical findings. The growth of cloud droplets near the cloud base is dominated by condensation. However, the growth of droplets near the onset of warm rain $\left(R_{\mathrm{e}}\right.$ approaches $\left.\sim 14 \mu \mathrm{m}\right)$ is dominated by coalescence (Rosenfeld et al., 2012, 2014). The observed differences in the vertical gradient of droplet growth suggest less efficient collision-coalescence processes and prolonged condensation processes, leading to delayed raindrop formation (Rosenfeld, 1999, 2000; Squires, 1958; Warner and Twomey, 1967). Such prolonged condensational growth of droplets implies increased condensed water loading, causing more latent heat release and thereby stronger updrafts under higher aerosol loading (Fan et al., 2009; Khain et al., 2005; Martins et al., 2011; Rosenfeld et al., 2008; van den Heever et al., 2011; Wang, 2005). Concurrently, smaller droplet $R_{\mathrm{e}}$ under polluted conditions results in a lower effective terminal velocity and higher cloud droplet mobility (Heiblum et al., 2016; Ilan et al., 2015). Under polluted conditions, then, the aerosol-induced stronger updrafts and enhanced buoyancy would push these smaller condensates above freezing level (Andreae et al., 2004; Rosenfeld and Lensky, 1998), which, in turn, would enhance liquid droplets above the freezing level. Nevertheless, the smaller droplets are less efficient in freezing, causing a delay in the ice- or mix-phase processes which provide sustenance for super-cooled liquid condensates above freezing level (Rosenfeld and Woodley, 2000). These hydrometeors encounter a greater number of supercooled liquid droplets while settling from a comparatively 

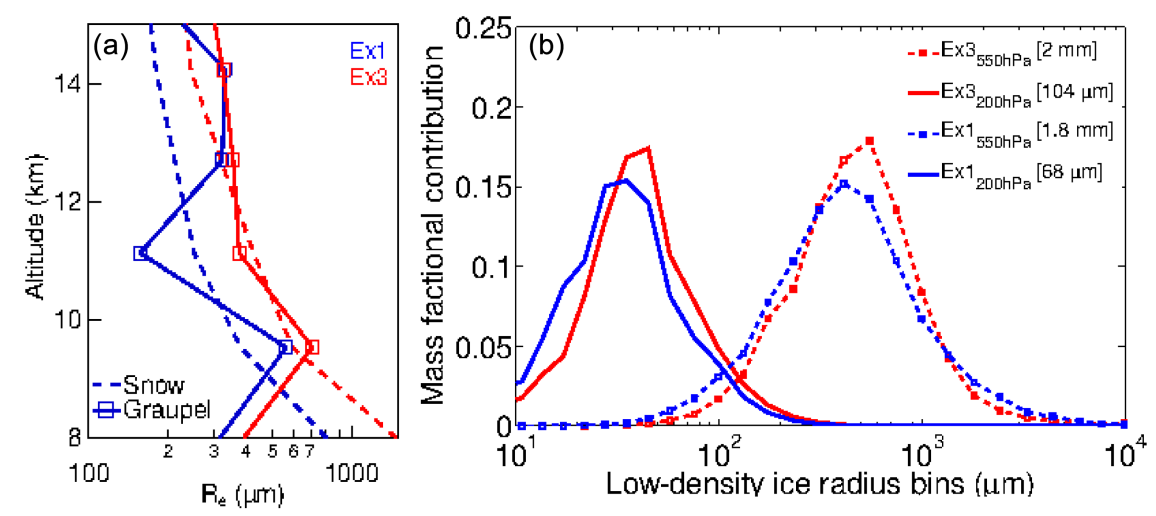

Figure 9. (a) Simulated mean snow (dashed) and graupel (open square symbol connected by solid line) $R_{\mathrm{e}}$ for low- (Ex1, blue) and high(Ex3, red) CCN scenario. (b) Simulated size distribution spectra of low-density ice particles for Ex1(blue) and Ex3 (red) at $550 \mathrm{hPa}$ (solid lines) and $200 \mathrm{hPa}$ (dashed lines). The fractional contribution is calculated by dividing the mass concentration of each bin with the total mass concentration.

higher altitude under gravity. Thus, an increased ice water accretion process (Ilotoviz et al., 2016) increases ice particle $R_{\mathrm{e}}$ under high aerosol loading. An increase in the water mass flux of the smaller droplets at higher altitudes, in principle, releases more latent heat from freezing and further invigorates the cloud system (Altaratz et al., 2014; Rosenfeld et al., 2008). Such aerosol-induced invigoration also implies the formation of ice-phase hydrometeors at higher altitudes by the freezing of small droplets (Altaratz et al., 2014). Such aerosol-induced invigorating of clouds ultimately results in wider and deeper clouds, with a higher mass concentration of ice-phase hydrometeors, which eventually fall to the surface (Figs. 3 and 5) (Andreae et al., 2004; Koren et al., 2005, 2012; Rosenfeld et al., 2008). Thus, the observed increase in daily rainfall with increasing aerosol loading over the ISMR (Fig. 3) could stem from the observed differences in warm phase dynamics and microphysics, which plausibly leads to cloud invigoration and thereby enhances the mass concentration of mixed-phase hydrometeors.

\subsection{Analysis of non-microphysical aerosol-cloud-rainfall association}

\subsubsection{Decoupling the role of meteorology}

Observational and modeled evidence of the microphysical impact of aerosol over the ISMR suggests causality in the observed relationship between aerosol-cloud and rainfall properties (Fig. 3). Here, we examined the plausible role of meteorology in our analyses. Figure 10 shows the correlation coefficients of RF, CF, and AOD with GDAS meteorological variables. The meteorological conditions favorable for deeper clouds and heavy rainfall were found to be associated with a reduction in AOD (Fig. 10). As expected, a positive correlation of $\mathrm{CF}$ and RF was observed with relative humidity. However, an increase in RH was negatively correlated with aerosol loading, suggesting that cloudy or wet condi- tions were associated with the reduction in aerosol loading. While CF and RF was found to be negatively correlated with geopotential height (mainly below $500 \mathrm{hPa}$ ), AOD was linearly correlated. This suggests that the formation of a lowpressure zone or the presence of high RH at lower atmosphere was favorable for cloud development and rain but not for aerosol accumulation. These features are consistent with that of heavy-rainfall periods of ISM, where the presence of a low-pressure zone over the ISMR (commonly known as monsoon depressions) is associated for the advection of more moisture at lower altitudes, more cloud condensation, and the occurrence of more rainfall. A recent modeling study has also shown that the propagation of a low-pressure system from the Bay of Bengal towards the Indian landmass, which brings moisture and heavy rainfall to the region during the monsoon, is also associated with a decrease in aerosol concentration over the region (Sarangi et al., 2015). The decrease might be a combined effect of ingestion by clouds, wet scavenging, and a dilution effect of relatively clean moist air masses from the ocean. A positive correlation of wind speed with $\mathrm{CF}$ and $\mathrm{RF}$ at an altitude above $400 \mathrm{hPa}$ was also associated with reduced AOD (Fig. 10). The high wind speed above $350 \mathrm{hPa}$ (Fig. 10) appears to provide a shearing effect on the cloud development process. Based on the correlation analysis, horizontal wind shear (between 500 and $200 \mathrm{hPa}$ ), relative humidity, and geopotential height (below $500 \mathrm{hPa}$ ) were identified as three key meteorological variables (magnitude of correlation coefficient $>0.25$ ) affecting cloud and rainfall properties in the ISMR.

Next, the datasets were segregated into low and high regimes of wind shear, calculated between 200 and $400 \mathrm{hPa}$, as well as for geopotential height and relative humidity at $800 \mathrm{hPa}$ pressure level (Fig. 11). The low versus high regimes illustrated that steeper positive gradients in AOD-cloud-RF associations were observed for high relative humidity and low geopotential height conditions, but the magnitude of the 


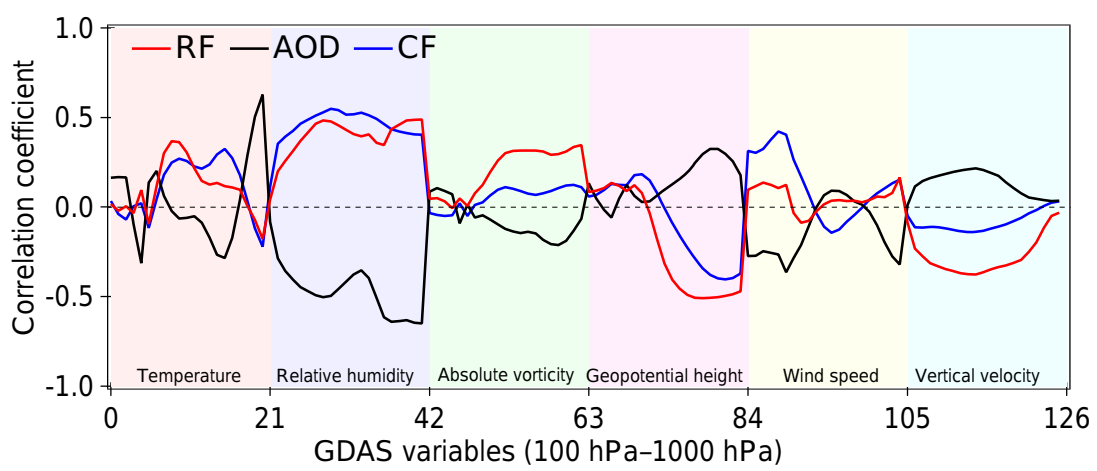

Figure 10. Correlation coefficients of accumulated daily rainfall, AOD, and cloud fraction with six GDAS meteorological variables over the ISMR. Different color shades along the $x$ axis indicate corresponding meteorological variable, and each color shade has 21 divisions, which represents the corresponding 21 model pressure levels from 100 to $1000 \mathrm{hPa}$ (left to right). Correlation analysis was performed at each model pressure level with all collocated samples between two variables (e.g., temperature and RF for $x$-axis values of $1-21$ in the case of the red line) over the ISMR region for JJAS 2002-2013.

positive gradient between RF (and PR)-AOD reduced under high wind shear cases. The spreading of the cloud due to high wind shear results in hydrometeors falling through relatively drier atmosphere making smaller droplets (in polluted condition); these are more susceptible to evaporation (Fan et al., 2009), thereby leading to the reduction in PR and RF. Thus, an orthogonal meteorological impact (Koren et al., 2010a, 2014) was evident on gradients of AOD-cloud-rainfall associations over the ISMR, where the $y$ intercept indicates the meteorology effect and the slope of correlation represents aerosol effect. We have also considered the combined effect of all the three key meteorological variables by dividing the datasets into eight regimes (alternate combination of higher and lower bins of RH, wind shear (WS), and geopotential height (GPH)). Our analysis illustrated (figure not shown) similar results as seen in Fig. 11; positive aerosol-cloudrainfall association was evident in all the eight sub-regimes along with a distinct orthogonal effect of ambient meteorological conditions.

Ground-based remote sensing, satellite observations, aircraft measurements, and modeling studies have documented that aerosols are mainly located within the boundary layer during the monsoon period over the ISMR (Mishra and Shibata, 2012; Misra et al., 2012; Sarangi et al., 2015). But some recent studies have reported that the transport of nearsurface aerosols to the free troposphere by mesoscale convection results in upper-level accumulation during the summer monsoon, termed the Asian tropopause aerosol layer (Chakraborty et al., 2015; Vernier et al., 2015). Therefore, another possible pathway through which meteorological covariability can influence our correlation analysis over the ISMR is due to the positive association between the magnitude of the Asian tropopause aerosol layer and AOD. However, the tropopause aerosol layer pathway results in insignificant enhancements of AOD during JJAS by $\sim 0.01-0.02$ over south Asia compared to the observed climatological mean AOD $(\sim 0.6)$ (Vernier et al., 2015; Yu et al., 2015). Thus, contributions of the Asian tropopause aerosol layer to the observed positive gradients (Fig. 3) can be assumed to be negligible.

\subsubsection{Examining the influence of the cloud contamination effect}

Here, we used radiosonde observations from eight stations in the ISMR (Table 2) to illustrate the humidification effect on satellite-retrieved AOD. The total number of cloudy profiles varied from 270 (Ranchi) to 1065 (Kolkata). The mean and standard deviation in RH for these selected profiles was calculated (for each station data) in two layers of 1.5 and $3 \mathrm{~km}$ from the surface. The bias in mean RH between shallower and deeper clouds for each station is also presented in Table 2. The range of variation in mean $\mathrm{RH}$ for each layer has been presented in Table 3. We found that with an increase in mean RH, the natural variance in RH decreased for both the layers within the ISMR. The mean and standard deviation of $\mathrm{RH}$ in the $1.5 \mathrm{~km}(3 \mathrm{~km})$ layer was found to be $84.3 \pm 13.2 \%$ $(84.7 \pm 13.5 \%)$ under cloudy conditions within the ISMR. At the same time, the bias in mean RH (associated with vertical change in cloud layer height) in 1.5 and $3.0 \mathrm{~km}$ layer was found to be 2.7 and $2.5 \%$, respectively. It can be seen that the bias was negligible compared to the natural variation present in RH during cloudy conditions in the ISMR. Using the parameterization developed in Bar-Or et al. (2012), the maximum change in AOD was estimated to be about 0.1 due to the humidification effect (Table 3). Thus, the uncertainties in our data analyses due to the aerosol humidification effect seem to be minimal. Note that the difference in clean and polluted conditions in this study (AOD of about 1.0) was nearly 1 order of magnitude higher than the estimated maximum change in AOD $(\sim 0.1)$ due to the humidification effect. Therefore, the observed positive associations between AOD and cloud or rainfall properties do not appear to be sig- 
(a)
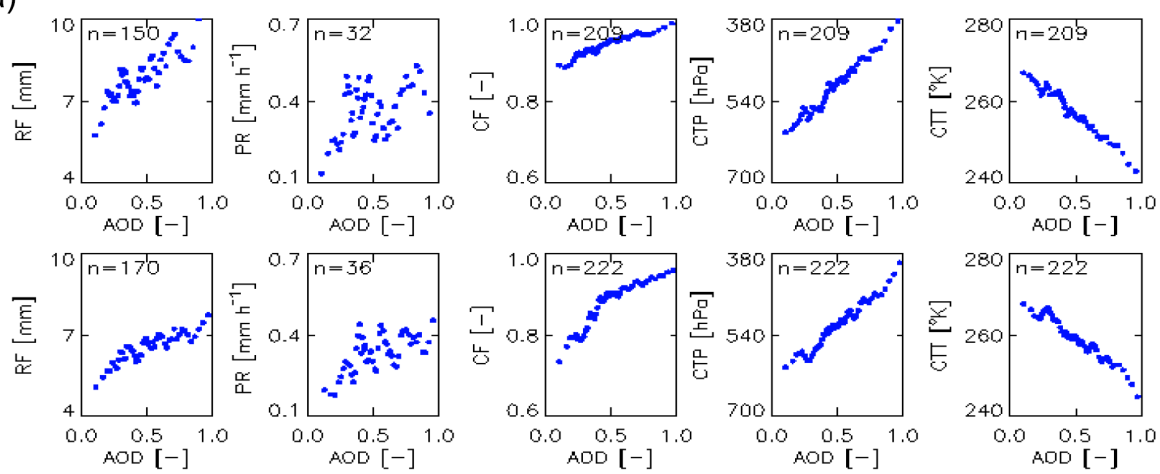

(b)
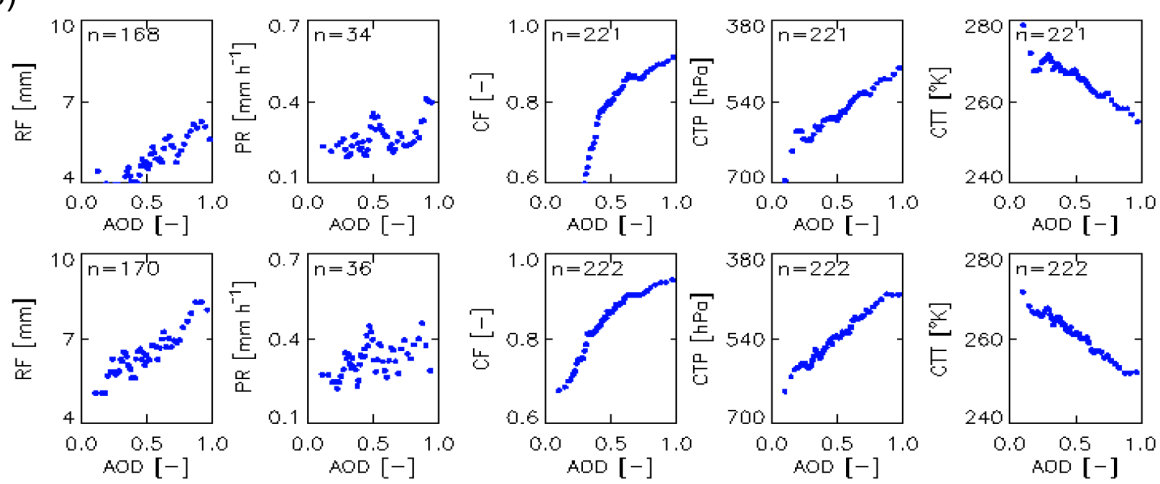

(c)
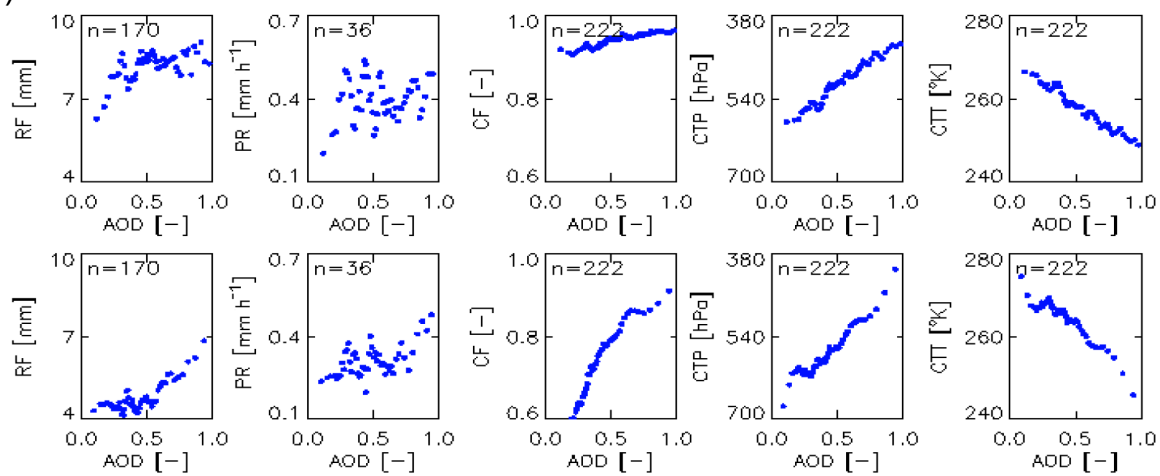

Figure 11. Associations of accumulated daily rainfall, precipitation rate, cloud fraction, cloud top pressure, and cloud top temperature with AOD. (a) Data slicing by the wind shear for the lower regime (0-33\%, top) and the higher regime (67-100\%, bottom). (b) Same as panel (a), except data slicing by the relative humidity. (c) Same as panel (a), except data slicing by the geopotential height. The methodology of creation of the scatter points was similar to that used for Fig. 3. Each scatter point is the average of these equal " $n$ " numbers of data points mentioned in each respective panel.

nificantly affected by aerosol growth due to humidification during cloudy conditions. In fact, the observed negative relationship between AOD and the increase in RH over the ISMR (Fig. 11) appears to dominate the otherwise expected higher hygroscopic growth of aerosols and supports the above argument.

\subsubsection{Investigating the effect of wet scavenging on aerosol-rainfall associations}

Contrary to the positive aerosol-cloud-rainfall associations shown by many satellite data studies across the globe, recent studies have illustrated a negative aerosol-rainfall association mainly over the tropical ocean region based on reanalysis dataset and global model simulations. This difference in sign of the association in modeling studies is mainly 
Table 3. Estimating change in AOD ( $\triangle \mathrm{AOD}$ ) due to variation in $\mathrm{RH}$. The hygroscopicity parameter, $k$ used in the estimation was taken as 0.1 and 0.2 to illustrate minimum and maximum change due to change in aerosol properties.

\begin{tabular}{lrr}
\hline & Layer $1.5 \mathrm{~km}$ & Layer $3 \mathrm{~km}$ \\
\hline Range of mean RH & $72-97$ & $71-98$ \\
RH scaled as distance & $0.02-0.13$ & $0.02-0.12$ \\
from nearest cloud & & \\
$\begin{array}{l}\text { Maximum } \Delta \text { (AOD) } \\
\text { for } k=0.1(0.2)\end{array}$ & $\sim 0.05(0.1)$ & $\sim 0.05(0.1)$ \\
\hline
\end{tabular}

attributed to the inclusion of the wet-scavenging effect in models and the probable lack of the same in satellite samples (Grandey et al., 2013, 2014; Yang et al., 2016). However, global modeling studies have their own inherent limitations and uncertainties in addressing aerosol-cloud-rainfall associations. Due to computational constraints, the global model simulations use grids with a coarse spatial resolution $(\sim 200 \mathrm{~km})$ and fall short of explicitly resolving the finescale cloud processes. Moreover, the convection parameterizations used to simulate cloud formation generally do not parameterize the aerosol indirect effect on clouds and thus on rainfall. By contrast, the observed relations using satellite datasets are on a fine scale and inclusive of the aerosol indirect effect. As a representative analysis, collocated AODrainfall measurements at hourly temporal resolution over IITK were used to illustrate the association between aerosolrainfall with and without the wet-scavenging effect. A positive association was found between rainfall amount and mean AOD values measured before the starting of rain events over IITK (NWS_IITK; red line in Fig. 12). A similar association was also found when all the available collocated AODrain amount samples over IITK were correlated (cyan line in Fig. 12), but the gradient was reduced by almost $50 \%$ compared to that of NWS_IITK. Thus, the positive association between aerosol-rainfall was evident even with the inclusion of the wet-scavenging effect in the sampling. Grandey et al. (2013) have also shown a similar amount of contribution of the wet-scavenging effect on the positive aerosolcloud association. The correlation of MODIS-AOD with RF (black line in Fig. 12) and PR (blue line in Fig. 12) values over the IITK grid also illustrated a positive association between aerosol and rainfall similar to the observed associations in Fig. 3. A high anthropogenic aerosol emission rate at the surface (Bond et al., 2004) and the rapid aerosol buildup within a few hours after the individual rainfall event over the ISMR (Jai Devi et al., 2011) might contribute towards reducing the impact of the wet-scavenging effect on the aerosol-cloud-rainfall analysis over the ISMR. This argument is also supported by a pattern seen in model results according to which negative aerosol-cloud-rainfall associations were usually prominent over ocean regions and positive

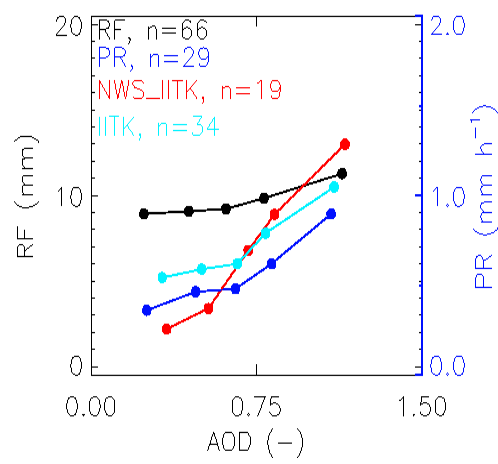

Figure 12. Associations of rainfall with collocated AERONETAOD measurements (within $\pm 4 \mathrm{~h}$ of the start or end of rainfall event) over IITK. The cyan line illustrates the scenario with the inclusion of the wet-scavenging effect (IITK), and the red line illustrates the scenario with no wet-scavenging effect (NWS_IITK). The association between daily rainfall and precipitation rate with MODIS-AOD over the IITK grid is also shown by black and blue lines, respectively. In each case, all the rainfall-AOD samples were sorted as a function of corresponding AOD values into five bins of 20 percentiles each. Each scatter point is the average of each bin and has $n$ number of data points.

aerosol-cloud-rainfall associations were found over continental conditions in global simulations (Grandey et al., 2013, 2014; Gryspeerdt et al., 2015; Yang et al., 2016). Unlike continental conditions, a lack of high emission rates at the ocean surface might also contribute to the dominant effect of wet scavenging on the aerosol-cloud-rainfall association. In addition, the cloudy pixels where rainfall actually occurs under continental conditions are usually a small fraction of the total area within a $1^{\circ} \times 1^{\circ}$ box, and, therefore, the reduction in mean AOD value of the $1^{\circ} \times 1^{\circ}$ box due to wet scavenging might not be a dominant phenomenon affecting the aerosol-cloud-rainfall gradients in Fig. 3. IITK-AERONET data analysis offers confidence in the observed position association for aerosol-cloud-rainfall and that it was not a misrepresentation due to possible uncertainties involved in the wet-scavenging effect in using satellite-retrieved AOD values. Indeed, it also showed that a more accurate representation of the wet-scavenging effect is essential to reducing uncertainty about the magnitude of the positive aerosol-rainfall gradient observed over the ISMR.

\section{Summary}

In this study, long-term satellite and in situ observational datasets were systematically analyzed to obtain new insights into aerosol-cloud-rainfall associations over the ISMR. An important finding is that the MODIS-retrieved cloud properties (CF, CTP, CTT), IMD in situ surface-accumulated rainfall, and TRMM-retrieved precipitation rate illustrated a positive association with increasing aerosol loading. Additional 
selective analysis over a smaller spatial region within the ISMR and separating the dataset into relatively shallower and deeper clouds also illustrated similar aerosol-cloud-rainfall associations, plausibly highlighting the robustness of these associations. A decrease in outgoing longwave radiation and an increase in outgoing shortwave radiation at the top of the atmosphere, with an increase in aerosol loading, further suggested a deepening of cloud systems over the ISMR.

Further, MODIS- and CloudSat-observed microphysical differences between low and high aerosol loading were investigated to gain a process-level understanding of the observed associations. A comparison of mean profiles of CTP $R_{\mathrm{e}}$ illustrated that an increase in aerosol loading is associated with a slower growth of $R_{\mathrm{e}}$ with altitude, indicating a reduction in coalescence efficiency and delay in initiation of warm rain. CloudSat-retrieved profiles showed that the liquid water content increased under high aerosol loading, mainly the supercooled liquid droplets above the freezing level. Simultaneously, the observed mass concentration and effective radius of ice-phase hydrometeors increased manifold under high aerosol loading. We also performed three idealized supercell simulations of a typical heavy-rainfall event over the ISMR by varying initial CCN concentrations. Modeling results were found to be in-line with our observational findings, showing that $\mathrm{CCN}$-induced initial suppression of warm phase processes along with an increase in updraft velocity lead to a movement of more water mass across freezing level; this results in an enhancement of ice-phase hydrometeor concentration and eventually in an intensification of surface rainfall under high $\mathrm{CCN}$ loading.

We understand the limitation that the influences of meteorological conditions are ideally difficult to separate from that of aerosol on the cloud-rainfall system. However, we have systematically shown that the positive aerosol-cloud-rainfall associations were present even in narrow regimes of key cloud-forming meteorological variables like RH, geopotential height, and wind shear. Further, the ambiguity involved in the humidification effect on retrieved AOD can also affect the positive gradients between aerosol and cloud-rainfall properties. Besides, AOD also suffers from substantial uncertainty in being representative of $\mathrm{CCN}$ concentration near the cloud base (Andreae, 2009) and in the inclusion of the wetscavenging effect in the AOD samples. These caveats may result in an overestimation of the observed positive gradients in aerosol-cloud-rainfall associations. Our analysis therefore cannot quantify the magnitude of gradients with confidence. However, this study certainly suggests a significant role of aerosol in rainfall properties via cloud invigoration over the ISMR. In the future, more observational studies on cloud formation and rain event timescales are warranted to accurately quantify the magnitude of the aerosol-cloud-rainfall association over the ISMR. Moreover, a consideration of aerosol microphysical effects is essential for the accurate prediction of monsoonal rainfall over this region of climatic importance.
Data availability. The rainfall gridded dataset is available from India Metrological Department, and all satellite datasets (GDAS, CloudSat, MODIS, CERES, TRMM) are available from their respective online data archives. In situ ground measurements of rainfall at the IITK site from 2006-2011 are available at http://www. mosdac.gov.in/, and those from 2012-2015 are available at http: //www.weather-risk.com (Tripathi, 2006). Request for data access can be made to the authors (at snt@iitk.ac.in). Radiosondes are accessible online from the University of Wyoming (downloaded from http://weather.uwyo.edu/upperair/sounding.html). AERONET data are available from https://aeronet.gsfc.nasa.gov/.

Competing interests. The authors declare that they have no conflict of interest.

Acknowledgements. This work was supported by India's Department of Science \& Technology (DST) Climate Change Program (grant no. DST/CCP/(NET-1)-PR 22/2012). Radiosondes were available online from the University of Wyoming. The authors also gratefully acknowledge the financial support given by the Earth System Science Organization, Ministry of Earth Sciences, Government of India (grant MM/NERC-MoES-03/2014/002) under the INCOMPASS campaign and the Monsoon Mission.

Edited by: Y. Qian

Reviewed by: M. G. Manoj and two anonymous referees

\section{References}

Abish, B. and Mohanakumar, K.: Role of fine mode aerosols in modulating cloud properties over industrial locations in north India, Ann. Geophys., 29, 1605-1612, doi:10.5194/angeo-291605-2011, 2011.

Ackerman, A. S., Toon, O. B., Stevens, D. E., Heymsfield, A. J., Ramanathan, V., and Welton, E. J.: Reduction of Tropical Cloudiness by Soot, Science, 288, 1042-1047, 2000.

Albrecht, B. A.: Aerosols, Cloud Microphysics, and Fractional Cloudiness, Science, 245, 1227-1230, 1989.

Altaratz, O., Bar-Or, R. Z., Wollner, U., and Koren, I.: Relative humidity and its effect on aerosol optical depth in the vicinity of convective clouds, Environ. Res. Lett., 8, 034025, doi:10.1088/1748-9326/8/3/034025, 2013.

Altaratz, O., Koren, I., Remer, L. A., and Hirsch, E.: Review: Cloud invigoration by aerosols - Coupling between microphysics and dynamics, Atmos. Res., 140-141, 38-60, 2014.

Andreae, M. O.: Correlation between cloud condensation nuclei concentration and aerosol optical thickness in remote and polluted regions, Atmos. Chem. Phys., 9, 543-556, doi:10.5194/acp-9-543-2009, 2009.

Andreae, M. O., Rosenfeld, D., Artaxo, P., Costa, A. A., Frank, G. P., Longo, K. M., and Silva-Dias, M. A. F.: Smoking Rain Clouds over the Amazon, Science, 303, 1337-1342, 2004.

Austin, R. T., Heymsfield, A. J., and Stephens, G. L.: Retrieval of ice cloud microphysical parameters using the CloudSat millimeter-wave radar and temperature, J. Geophys. Res.Atmos., 114, D00A23, doi:10.1029/2008JD010049, 2009. 
Bar-Or, R. Z., Koren, I., Altaratz, O., and Fredj, E.: Radiative properties of humidified aerosols in cloudy environment, Atmos. Res., 118, 280-294, 2012.

Bhattu, D. and Tripathi, S. N.: Inter-seasonal variability in sizeresolved CCN properties at Kanpur, India, Atmos. Environ., 85, 161-168, 2014

Bollasina, M. A., Ming, Y., and Ramaswamy, V.: Anthropogenic Aerosols and the Weakening of the South Asian Summer Monsoon, Science, 334, 502-505, 2011.

Bond, T. C., Streets, D. G., Yarber, K. F., Nelson, S. M., Woo, J.-H., and Klimont, Z.: A technology-based global inventory of black and organic carbon emissions from combustion, J. Geophys. Res.-Atmos., 109, D14203, doi:10.1029/2003JD003697, 2004.

Boucher, O. and Quaas, J.: Water vapour affects both rain and aerosol optical depth, Nat. Geosci., 6, 4-5, 2013.

Chakraborty, S., Fu, R., Wright, J. S., and Massie, S. T.: Relationships between convective structure and transport of aerosols to the upper troposphere deduced from satellite observations, J. Geophys. Res.-Atmos., 120, 6515-6536, 2015.

Chakraborty, S., Fu, R., Massie, S. T., and Stephens, G.: Relative influence of meteorological conditions and aerosols on the lifetime of mesoscale convective systems, P. Natl. Acad. Sci. USA, 113, 7426-7431, 2016.

Corrigan, C. E., Ramanathan, V., and Schauer, J. J.: Impact of monsoon transitions on the physical and optical properties of aerosols, J. Geophys. Res.-Atmos., 111, D18208, doi:10.1029/2005JD006370, 2006.

Dagan, G., Koren, I., and Altaratz, O.: Competition between core and periphery-based processes in warm convective clouds - from invigoration to suppression, Atmos. Chem. Phys., 15, 2749 2760, doi:10.5194/acp-15-2749-2015, 2015.

Dey, S. and Di Girolamo, L.: A decade of change in aerosol properties over the Indian subcontinent, Geophys. Res. Lett., 38, L14811, doi:10.1029/2011GL048153, 2011.

Dubovik, O. and King, M. D.: A flexible inversion algorithm for retrieval of aerosol optical properties from Sun and sky radiance measurements, J. Geophys. Res.-Atmos., 105, 20673-20696, 2000.

Durre, I., Vose, R. S., and Wuertz, D. B.: Overview of the Integrated Global Radiosonde Archive, J. Climate, 19, 53-68, 2006.

Fan, J., Yuan, T., Comstock, J. M., Ghan, S., Khain, A., Leung, L. R., Li, Z., Martins, V. J., and Ovchinnikov, M.: Dominant role by vertical wind shear in regulating aerosol effects on deep convective clouds, J. Geophys. Res.-Atmos., 114, D22206, doi:10.1029/2009JD012352, 2009.

Fan, J., Leung, L. R., Rosenfeld, D., Chen, Q., Li, Z., Zhang, J., and Yan, H.: Microphysical effects determine macrophysical response for aerosol impacts on deep convective clouds, P. Natl. Acad. Sci. USA, 110, E4581-E4590, 2013.

Feingold, G., Remer, L. A., Ramaprasad, J., and Kaufman, Y. J.: Analysis of smoke impact on clouds in Brazilian biomass burning regions: An extension of Twomey's approach, J. Geophys. Res.-Atmos., 106, 22907-22922, 2001.

Feingold, G., McComiskey, A., Yamaguchi, T., Johnson, J. S., Carslaw, K. S., and Schmidt, K. S.: New approaches to quantifying aerosol influence on the cloud radiative effect, P. Natl. Acad. Sci. USA, 113, 5812-5819, 2016.
Fitzgerald, J. W. and Spyers-Duran, P. A.: Changes in Cloud Nucleus Concentration and Cloud Droplet Size Distribution Associated with Pollution from St. Louis, J. Appl. Meteorol., 12, 511516, 1973.

Forster, P., Ramaswamy, V., Artaxo, P., Berntsen, T., Betts, R., Fahey, D. W., Haywood, J., Lean, J., Lowe, D. C., Myhre, G., Nganga, J., Prinn, R., Raga, G., Schulz, M., and Van Dorland, R. Changes in Atmospheric Constituents and in Radiative Forcing, in: Climate Change 2007: The Physical Science Basis. Contribution of Working Group I to the Fourth Assessment Report of the Intergovernmental Panel on Climate Change Rep., Cambridge, UK and New York, NY, USA, 2007.

Freud, E., Rosenfeld, D., and Kulkarni, J. R.: Resolving both entrainment-mixing and number of activated $\mathrm{CCN}$ in deep convective clouds, Atmos. Chem. Phys., 11, 12887-12900, doi:10.5194/acp-11-12887-2011, 2011.

Gadgil, S.: The Indian Monsoon and its Variability, Annu. Rev. Earth Pl. Sc., 31, 429-467, 2003.

Ganguly, D., Rasch, P. J., Wang, H., and Yoon, J.-H.: Climate response of the South Asian monsoon system to anthropogenic aerosols, J. Geophys. Res.-Atmos., 117, D13209, doi:10.1029/2012JD017508, 2012.

Gonçalves, W. A., Machado, L. A. T., and Kirstetter, P.-E.: Influence of biomass aerosol on precipitation over the Central Amazon: an observational study, Atmos. Chem. Phys., 15, 6789-6800, doi:10.5194/acp-15-6789-2015, 2015.

Goswami, B. N., Venugopal, V., Sengupta, D., Madhusoodanan, M. S., and Xavier, P. K.: Increasing Trend of Extreme Rain Events Over India in a Warming Environment, Science, 314, 14421445, 2006.

Grandey, B. S., Stier, P., and Wagner, T. M.: Investigating relationships between aerosol optical depth and cloud fraction using satellite, aerosol reanalysis and general circulation model data, Atmos. Chem. Phys., 13, 3177-3184, doi:10.5194/acp-13-31772013, 2013.

Grandey, B. S., Gururaj, A., Stier, P., and Wagner, T. M.: Rainfallaerosol relationships explained by wet scavenging and humidity, Geophys. Res. Lett., 41, 5678-5684, 2014.

Gryspeerdt, E., Stier, P., and Grandey, B. S.: Cloud fraction mediates the aerosol optical depth-cloud top height relationship, Geophys. Res. Lett., 41, 3622-3627, 2014.

Gryspeerdt, E., Stier, P., White, B. A., and Kipling, Z.: Wet scavenging limits the detection of aerosol effects on precipitation, Atmos. Chem. Phys., 15, 7557-7570, doi:10.5194/acp-15-75572015, 2015.

Harikishan, G., Padmakumari, B., Maheskumar, R. S., Pandithurai, G., and Min, Q. L.: Aerosol indirect effects from ground-based retrievals over the rain shadow region in Indian subcontinent, J. Geophys. Res.-Atmos., 121, 2369-2382, 2016.

Hazra, A., Goswami, B. N., and Chen, J.-P.: Role of Interactions between Aerosol Radiative Effect, Dynamics, and Cloud Microphysics on Transitions of Monsoon Intraseasonal Oscillations, J. Atmos. Sci., 70, 2073-2087, 2013.

Heiblum, R. H., Koren, I., and Altaratz, O.: New evidence of cloud invigoration from TRMM measurements of rain center of gravity, Geophys. Res. Lett., 39, L08803, doi:10.1029/2012GL051158, 2012.

Heiblum, R. H., Altaratz, O., Koren, I., Feingold, G., Kostinski, A. B., Khain, A. P., Ovchinnikov, M., Fredj, E., Dagan, G., Pinto, L., 
Yaish, R., and Chen, Q.: Characterization of cumulus cloud fields using trajectories in the center of gravity versus water mass phase space: 2. Aerosol effects on warm convective clouds, J. Geophys. Res.-Atmos., 121, 6356-6373, 2016.

Holben, B. N., Eck, T. F., Slutsker, I., Tanré, D., Buis, J. P., Setzer, A., Vermote, E., Reagan, J. A., Kaufman, Y. J., Nakajima, T., Lavenu, F., Jankowiak, I., and Smirnov, A.: AERONET - A Federated Instrument Network and Data Archive for Aerosol Characterization, Remote Sens. Environ., 66, 1-16, 1998.

Huffman, G., Adler, R., Bolvin, D., and Nelkin, E.: The TRMM Multi-Satellite Precipitation Analysis (TMPA), in: Satellite Rainfall Applications for Surface Hydrology, edited by: Gebremichael, M. and Hossain, F., 3-22, Springer Netherlands, doi:10.1007/978-90-481-2915-7, 2010.

Iguchi, T., Matsui, T., Shi, J. J., Tao, W.-K., Khain, A. P., Hou, A., Cifelli, R., Heymsfield, A., and Tokay, A.: Numerical analysis using WRF-SBM for the cloud microphysical structures in the C3VP field campaign: Impacts of supercooled droplets and resultant riming on snow microphysics, J. Geophys. Res.-Atmos., 117, D23206, doi:10.1029/2012JD018101, 2012.

Ilan, K., Orit, A., and Guy, D.: Aerosol effect on the mobility of cloud droplets, Environ. Res. Lett., 10, 104011, doi:10.1088/1748-9326/10/10/104011, 2015.

Ilotoviz, E., Khain, A. P., Benmoshe, N., Phillips, V. T. J., and Ryzhkov, A. V.: Effect of Aerosols on Freezing Drops, Hail, and Precipitation in a Midlatitude Storm, J. Atmos. Sci., 73, 109-144, 2016.

Jai Devi, J., Tripathi, S. N., Gupta, T., Singh, B. N., Gopalakrishnan, V., and Dey, S.: Observation-based 3-D view of aerosol radiative properties over Indian Continental Tropical Convergence Zone: implications to regional climate, Tellus B, 63, 971-989, 2011.

Kaufman, Y. J., Tanre, D., and Boucher, O.: A satellite view of aerosols in the climate system, Nature, 419, 215-223, 2002.

Khain, A.: Notes on state-of-the-art investigations of aerosol effects on precipitation: a critical review, Environ. Res. Lett., 4, 015004 , doi:10.1088/1748-9326/4/1/015004, 2009.

Khain, A. and Lynn, B.: Simulation of a supercell storm in clean and dirty atmosphere using weather research and forecast model with spectral bin microphysics, J. Geophys. Res.-Atmos., 114, D19209, doi:10.1029/2009JD011827, 2009.

Khain, A., Ovtchinnikov, M., Pinsky, M., Pokrovsky, A., and Krugliak, H.: Notes on the state-of-the-art numerical modeling of cloud microphysics, Atmos. Res., 55, 159-224, 2000.

Khain, A., Pokrovsky, A., Pinsky, M., Seifert, A., and Phillips, V.: Simulation of Effects of Atmospheric Aerosols on Deep Turbulent Convective Clouds Using a Spectral Microphysics MixedPhase Cumulus Cloud Model. Part I: Model Description and Possible Applications, J. Atmos. Sci., 61, 2963-2982, 2004.

Khain, A., Rosenfeld, D., and Pokrovsky, A.: Aerosol impact on the dynamics and microphysics of deep convective clouds, Q. J. Roy. Meteor. Soc., 131, 2639-2663, 2005.

Khain, A., BenMoshe, N., and Pokrovsky, A.: Factors Determining the Impact of Aerosols on Surface Precipitation from Clouds: An Attempt at Classification, J. Atmos. Sci., 65, 1721-1748, 2008.

Konwar, M., Maheskumar, R. S., Kulkarni, J. R., Freud, E., Goswami, B. N., and Rosenfeld, D.: Aerosol control on depth of warm rain in convective clouds, J. Geophys. Res.-Atmos., 117, D13204, doi:10.1029/2012JD017585, 2012.
Koren, I., Kaufman, Y. J., Remer, L. A., and Martins, J. V.: Measurement of the Effect of Amazon Smoke on Inhibition of Cloud Formation, Science, 303, 1342-1345, 2004.

Koren, I., Kaufman, Y. J., Rosenfeld, D., Remer, L. A., and Rudich, Y.: Aerosol invigoration and restructuring of Atlantic convective clouds, Geophys. Res. Lett., 32, L14828, doi:10.1029/2005GL023187, 2005.

Koren, I., Martins, J. V., Remer, L. A., and Afargan, H.: Smoke Invigoration Versus Inhibition of Clouds over the Amazon, Science, 321, 946-949, 2008.

Koren, I., Feingold, G., and Remer, L. A.: The invigoration of deep convective clouds over the Atlantic: aerosol effect, meteorology or retrieval artifact?, Atmos. Chem. Phys., 10, 8855-8872, doi:10.5194/acp-10-8855-2010, 2010a.

Koren, I., Remer, L. A., Altaratz, O., Martins, J. V., and Davidi, A.: Aerosol-induced changes of convective cloud anvils produce strong climate warming, Atmos. Chem. Phys., 10, 5001-5010, doi:10.5194/acp-10-5001-2010, 2010b.

Koren, I., Altaratz, O., Remer, L. A., Feingold, G., Martins, J. V., and Heiblum, R. H.: Aerosol-induced intensification of rain from the tropics to the mid-latitudes, Nat. Geosci., 5, 118-122, 2012.

Koren, I., Dagan, G., and Altaratz, O.: From aerosol-limited to invigoration of warm convective clouds, Science, 344, 1143-1146, 2014.

Kourtidis, K., Stathopoulos, S., Georgoulias, A. K., Alexandri, G., and Rapsomanikis, S.: A study of the impact of synoptic weather conditions and water vapor on aerosol-cloud relationships over major urban clusters of China, Atmos. Chem. Phys., 15, 1095510964, doi:10.5194/acp-15-10955-2015, 2015.

Krishnamurthy, V. and Shukla, J.: Intraseasonal and Seasonally Persisting Patterns of Indian Monsoon Rainfall, J. Climate, 20, 3-20, 2007.

Krishnamurthy, V. and Shukla, J.: Seasonal persistence and propagation of intraseasonal patterns over the Indian monsoon region, Clim. Dynam., 30, 353-369, 2008.

Lau, K. M. and Kim, K. M.: Observational relationships between aerosol and Asian monsoon rainfall, and circulation, Geophys. Res. Lett., 33, L21810, doi:10.1029/2006GL027546, 2006.

Lee, S.-S.: Atmospheric science: Aerosols, clouds and climate, Nat. Geosci., 4, 826-827, 2011.

Lensky, I. M. and Rosenfeld, D.: The time-space exchangeability of satellite retrieved relations between cloud top temperature and particle effective radius, Atmos. Chem. Phys., 6, 2887-2894, doi:10.5194/acp-6-2887-2006, 2006.

Li, Z., Niu, F., Fan, J., Liu, Y., Rosenfeld, D., and Ding, Y.: Longterm impacts of aerosols on the vertical development of clouds and precipitation, Nat. Geosci., 4, 888-894, 2011.

Li, Z., Lau, W. K.-M., Ramanathan, V., Wu, G., Ding, Y., Manoj, M. G., Liu, J., Qian, Y., Li, J., Zhou, T., Fan, J., Rosenfeld, D., Ming, Y., Wang, Y., Huang, J., Wang, B., Xu, X., Lee, S.-S., Cribb, M., Zhang, F., Yang, X., Zhao, C., Takemura, T., Wang, K., Xia, X., Yin, Y., Zhang, H., Guo, J., Zhai, P. M., Sugimoto, N., Babu, S. S., and Brasseur, G. P.: Aerosol and monsoon climate interactions over Asia, Rev. Geophys., 54, 866-929, 2016.

Lohmann, U. and Feichter, J.: Global indirect aerosol effects: a review, Atmos. Chem. Phys., 5, 715-737, doi:10.5194/acp-5-7152005, 2005.

Lynn, B. and Khain, A.: Utilization of spectral bin microphysics and bulk parameterization schemes to simulate the cloud structure 
and precipitation in a mesoscale rain event, J. Geophys. Res.Atmos., 112, D22205, doi:10.1029/2007JD008475, 2007.

Manoj, M. G., Devara, P. C. S., Safai, P. D., and Goswami, B. N.: Absorbing aerosols facilitate transition of Indian monsoon breaks to active spells, Clim. Dynam., 37, 2181-2198, 2011.

Manoj, M. G., Devara, P. C. S., Joseph, S., and Sahai, A. K.: Aerosol indirect effect during the aberrant Indian Summer Monsoon breaks of 2009, Atmos. Environ., 60, 153-163, 2012.

Martins, J. V., Marshak, A., Remer, L. A., Rosenfeld, D., Kaufman, Y. J., Fernandez-Borda, R., Koren, I., Correia, A. L., Zubko, V., and Artaxo, P.: Remote sensing the vertical profile of cloud droplet effective radius, thermodynamic phase, and temperature, Atmos. Chem. Phys., 11, 9485-9501, doi:10.5194/acp-11-94852011, 2011.

Mishra, A. K. and Shibata, T.: Climatological aspects of seasonal variation of aerosol vertical distribution over central IndoGangetic belt (IGB) inferred by the space-borne lidar CALIOP, Atmos. Environ., 46, 365-375, 2012.

Misra, A., Tripathi, S. N., Kaul, D. S., and Welton, E. J.: Study of MPLNET-Derived Aerosol Climatology over Kanpur, India, and Validation of CALIPSO Level 2 Version 3 Backscatter and Extinction Products, J. Atmos. Ocean. Tech., 29, 1285-1294, 2012.

Myhre, G., Stordal, F., Johnsrud, M., Kaufman, Y. J., Rosenfeld, D., Storelvmo, T., Kristjansson, J. E., Berntsen, T. K., Myhre, A., and Isaksen, I. S. A.: Aerosol-cloud interaction inferred from MODIS satellite data and global aerosol models, Atmos. Chem. Phys., 7, 3081-3101, doi:10.5194/acp-7-3081-2007, 2007.

Padma Kumari, B. and Goswami, B. N.: Seminal role of clouds on solar dimming over the Indian monsoon region, Geophys. Res. Lett., 37, L06703, doi:10.1029/2009GL042133, 2010.

Pai, D. S., Sridhar, L., Rajeevan, M., Sreejith, O. P., Satbhai, N. S., and Mukhopadhyay, B.: Development and analysis of a new high spatial resolution $\left(0.25^{\circ} \times 0.25^{\circ}\right)$ long period $(1901-2010)$ daily gridded rainfall data set over India Rep., National Climate Centre, India Meteorological Department, Pune, India, 2013.

Pai, D. S., Sridhar, L., Rajeevan, M., Sreejith, O. P., Satbhai, N. S., and Mukhopadhyay, B.: Analysis of daily rainfall events over India using a new long period (1901-2010) high resolution $\left(0.25^{\circ} \times 0.25^{\circ}\right)$ gridded rainfall data set, Clim. Dynam., $45,755-$ 776, doi:10.1007/s00382-014-2307-1, 2014.

Pandithurai, G., Dipu, S., Prabha, T. V., Maheskumar, R. S., Kulkarni, J. R., and Goswami, B. N.: Aerosol effect on droplet spectral dispersion in warm continental cumuli, J. Geophys. Res.-Atmos., 117, D16202, doi:10.1029/2011JD016532, 2012.

Panicker, A. S., Pandithurai, G., and Dipu, S.: Aerosol indirect effect during successive contrasting monsoon seasons over Indian subcontinent using MODIS data, Atmos. Environ., 44, 19371943, 2010.

Parrish, D. F. and Derber, J. C.: The National Meteorological Center's Spectral Statistical-Interpolation Analysis System, Mon. Weather Rev., 120, 1747-1763, 1992.

Pinsky, M., Mazin, I. P., Korolev, A., and Khain, A.: Supersaturation and Diffusional Droplet Growth in Liquid Clouds, J. Atmos. Sci., 70, 2778-2793, 2013.

Platnick, S., King, M. D., Ackerman, S. A., Menzel, W. P., Baum, B. A., Riedi, J. C., and Frey, R. A.: The MODIS cloud products: algorithms and examples from Terra, IEEE T. Geosci. Remote, 41, 459-473, 2003.
Prabha, T. V., Khain, A., Maheshkumar, R. S., Pandithurai, G., Kulkarni, J. R., Konwar, M., and Goswami, B. N.: Microphysics of Premonsoon and Monsoon Clouds as Seen from In Situ Measurements during the Cloud Aerosol Interaction and Precipitation Enhancement Experiment (CAIPEEX), J. Atmos. Sci., 68, 18821901, 2011.

Prabha, T. V., Patade, S., Pandithurai, G., Khain, A., Axisa, D., Pradeep-Kumar, P., Maheshkumar, R. S., Kulkarni, J. R., and Goswami, B. N.: Spectral width of premonsoon and monsoon clouds over Indo-Gangetic valley, J. Geophys. Res.-Atmos., 117, D20205, doi:10.1029/2011JD016837, 2012.

Preethi, B. and Revadekar, J. V.: Kharif foodgrain yield and daily summer monsoon precipitation over India, Int. J. Climatol., 33, 1978-1986, 2013.

Rajeevan, M., Bhate, J., and Jaswal, A. K.: Analysis of variability and trends of extreme rainfall events over India using 104 years of gridded daily rainfall data, Geophys. Res. Lett., 35, L18707, doi:10.1029/2008GL035143, 2008.

Ramachandran, S. and Kedia, S.: Aerosol, clouds and rainfall: interannual and regional variations over India, Clim. Dynam., 40, 1591-1610, 2013.

Ramanathan, V. and Carmichael, G.: Global and regional climate changes due to black carbon, Nat. Geosci., 1, 221-227, 2008.

Ramanathan, V., Crutzen, P. J., Kiehl, J. T., and Rosenfeld, D.: Aerosols, Climate, and the Hydrological Cycle, Science, 294, 2119-2124, 2001.

Remer, L. A., Kaufman, Y. J., Tanré, D., Mattoo, S., Chu, D. A., Martins, J. V., Li, R.-R., Ichoku, C., Levy, R. C., Kleidman, R. G., Eck, T. F., Vermote, E., and Holben, B. N.: The MODIS Aerosol Algorithm, Products, and Validation, J. Atmos. Sci., 62, 947-973, 2005.

Rosenfeld, D.: TRMM observed first direct evidence of smoke from forest fires inhibiting rainfall, Geophys. Res. Lett., 26, 31053108, 1999.

Rosenfeld, D.: Suppression of Rain and Snow by Urban and Industrial Air Pollution, Science, 287, 1793-1796, 2000.

Rosenfeld, D. and Lensky, I. M.: Satellite-Based Insights into Precipitation Formation Processes in Continental and Maritime Convective Clouds, B. Am. Meteorol. Soc., 79, 2457-2476, 1998.

Rosenfeld, D. and Woodley, W. L.: Deep convective clouds with sustained supercooled liquid water down to $-37.5^{\circ} \mathrm{C}$, Nature, 405, 440-442, 2000.

Rosenfeld, D., Lohmann, U., Raga, G. B., O’Dowd, C. D., Kulmala, M., Fuzzi, S., Reissell, A., and Andreae, M. O.: Flood or Drought: How Do Aerosols Affect Precipitation?, Science, 321, 1309-1313, 2008.

Rosenfeld, D., Wang, H., and Rasch, P. J.: The roles of cloud drop effective radius and LWP in determining rain properties in marine stratocumulus, Geophys. Res. Lett., 39, L13801, doi:10.1029/2012GL052028, 2012.

Rosenfeld, D., Andreae, M. O., Asmi, A., Chin, M., de Leeuw, G., Donovan, D. P., Kahn, R., Kinne, S., Kivekäs, N., Kulmala, M., Lau, W., Schmidt, K. S., Suni, T., Wagner, T., Wild, M., and Quaas, J.: Global observations of aerosol-cloud-precipitationclimate interactions, Rev. Geophys., 52, 750-808, 2014.

Sarangi, C., Tripathi, S. N., Tripathi, S., and Barth, M. C.: Aerosolcloud associations over Gangetic Basin during a typical monsoon depression event using WRF-Chem simulation, J. Geophys. Res.-Atmos., 120, 10974-10995, 2015. 
Seiki, T. and Nakajima, T.: Aerosol Effects of the Condensation Process on a Convective Cloud Simulation, J. Atmos. Sci., 71, 833-853, 2014.

Sengupta, K., Dey, S., and Sarkar, M.: Structural evolution of monsoon clouds in the Indian CTCZ, Geophys. Res. Lett., 40, 52955299, doi:10.1002/grl.50970, 2013.

Shepard, D.: A two-dimensional interpolation function for irregularly-spaced data, in: Proceedings of the 23rd ACM national conference, 27-29 August 1968, New York, NY, USA, ACM, 517-524, doi:10.1145/800186.810616, 1968.

Shrestha, P. and Barros, A. P.: Joint spatial variability of aerosol, clouds and rainfall in the Himalayas from satellite data, Atmos. Chem. Phys., 10, 8305-8317, doi:10.5194/acp-10-8305-2010, 2010.

Small, J. D., Jiang, J. H., Su, H., and Zhai, C.: Relationship between aerosol and cloud fraction over Australia, Geophys. Res. Lett., 38, L23802, doi:10.1029/2011GL049404, 2011.

Squires, P.: The Microstructure and Colloidal Stability of Warm Clouds, Tellus, 10, 256-261, 1958.

Squires, P. and Twomey, S.: The Relation Between Cloud Droplet Spectra and the Spectrum of Cloud Nuclei, in: Physics of Precipitation: Proceedings of the Cloud Physics Conference, Woods Hole, Massachusetts, USA, 3-5 June 1959, American Geophysical Union, 211-219, 2013.

Stephens, G. L., Vane, D. G., Boain, R. J., Mace, G. G., Sassen, K., Wang, Z., Illingworth, A. J., O'Connor, E. J., Rossow, W. B., Durden, S. L., Miller, S. D., Austin, R. T., Benedetti, A., Mitrescu, C., and the CloudSat Science Team: The Cloudsat Mission and the A-Train, B. Am. Meteorol. Soc., 83, 1771-1790, 2002.

Tao, W.-K., Chen, J.-P., Li, Z., Wang, C., and Zhang, C.: Impact of aerosols on convective clouds and precipitation, Rev. Geophys., 50, RG2001, doi:10.1029/2011RG000369, 2012.

Ten Hoeve, J. E., Remer, L. A., and Jacobson, M. Z.: Microphysical and radiative effects of aerosols on warm clouds during the Amazon biomass burning season as observed by MODIS: impacts of water vapor and land cover, Atmos. Chem. Phys., 11, 3021-3036, doi:10.5194/acp-11-3021-2011, 2011.

Trenberth, K. E., Fasullo, J. T., and Kiehl, J.: Earth's global energy budget, B. Am. Meteorol. Soc., 90, 311-323, 2009.

Tripathi, S. N., Dey, S., Chandel, A., Srivastava, S., Singh, R. P., and Holben, B. N.: Comparison of MODIS and AERONET derived aerosol optical depth over the Ganga Basin, India, Ann. Geophys., 23, 1093-1101, doi:10.5194/angeo-23-1093-2005, 2005.

Tripathi, S. N.: In-situ measured rainfall over IIT Kanpur, Indian Institute of Technology, Kanpur, available at: http://www.mosdac. gov.in/ (last access: April 2017), 2006.
Tripathi, S. N., Pattnaik, A., and Dey, S.: Aerosol indirect effect over Indo-Gangetic plain, Atmos. Environ., 41, 7037-7047, 2007.

Twomey, S.: Pollution and the planetary albedo, Atmos. Environ., 8, 1251-1256, 1974.

Twomey, S.: The Influence of Pollution on the Shortwave Albedo of Clouds, J. Atmos. Sci., 34, 1149-1152, 1977.

van den Heever, S. C., Stephens, G. L., and Wood, N. B.: Aerosol indirect effects on tropical convection characteristics under conditions of radiative-convective equilibrium, J. Atmos. Sci., 68, 699-718, 2011.

Vernier, J. P., Fairlie, T. D., Natarajan, M., Wienhold, F. G., Bian, J., Martinsson, B. G., Crumeyrolle, S., Thomason, L. W., and Bedka, K. M.: Increase in upper tropospheric and lower stratospheric aerosol levels and its potential connection with Asian pollution, J. Geophys. Res.-Atmos., 120, 1608-1619, 2015.

Wang, C.: A modeling study of the response of tropical deep convection to the increase of cloud condensation nuclei concentration: 1. Dynamics and microphysics, J. Geophys. Res.-Atmos., 110, D21211, doi:10.1029/2004JD005720, 2005.

Warner, J. and Twomey, S.: The Production of Cloud Nuclei by Cane Fires and the Effect on Cloud Droplet Concentration, J. Atmos. Sci., 24, 704-706, 1967.

Webster, P. J., Magaña, V. O., Palmer, T. N., Shukla, J., Tomas, R. A., Yanai, M., and Yasunari, T.: Monsoons: Processes, predictability, and the prospects for prediction, J. Geophys. Res.Oceans, 103, 14451-14510, 1998.

Wielicki, B. A., Barkstrom, B. R., Harrison, E. F., Lee, R. B., Louis Smith, G., and Cooper, J. E.: Clouds and the Earth's Radiant Energy System (CERES): An Earth Observing System Experiment, B. Am. Meteorol. Soc., 77, 853-868, 1996.

Yan, H., Li, Z., Huang, J., Cribb, M., and Liu, J.: Long-term aerosolmediated changes in cloud radiative forcing of deep clouds at the top and bottom of the atmosphere over the Southern Great Plains, Atmos. Chem. Phys., 14, 7113-7124, doi:10.5194/acp-14-71132014, 2014.

Yang, Y., Russell, L. M., Lou, S., Liu, Y., Singh, B., and Ghan, S. J.: Rain-aerosol relationships influenced by wind speed, Geophys. Res. Lett., 43, 2267-2274, 2016.

Yu, P., Toon, O. B., Neely, R. R., Martinsson, B. G., and Brenninkmeijer, C. A. M.: Composition and physical properties of the Asian Tropopause Aerosol Layer and the North American Tropospheric Aerosol Layer, Geophys. Res. Lett., 42, 2540-2546, 2015. 